Word count: abstract -110 (short), 249 (long); main text - 12,323; references - 6,021; total (including abstracts, main text, figures, tables, captions, references) - 19,571)

\title{
Implicit Computation and the Origins of Knowledge
}

Randolph C. Grace, Nicola J. Morton, Matt Grice, Anna J. Wilson \& Simon Kemp

University of Canterbury

Christchurch, New Zealand

Emails: randolph.grace@canterbury.ac.nz; nicky.morton@pg.canterbury.ac.nz;

gricematt@myvuw.ac.nz; ajwilsonkiwi@gmail.com; simon.kemp@ canterbury.ac.nz

Running title: Implicit Computation 
Short Abstract (110 words)

Infants have 'core knowledge systems' that support basic intuitions about the world including objects and their motion, space, number, and time. What is the origin of these systems, and what is their nature? We propose that core knowledge systems are based on an ability to form representations of the environment with algebraic structure - that is, on implicit computation. Why do organisms have this ability? Either the geometric invariants of the world have been internalized by natural selection, or mathematical structure is intrinsic to the mind. Implicit computation is a linchpin with potential to unlock some of the most fundamental questions about the connections between the mind, mathematics, and the world.

Long Abstract (249 words)

Human infants have 'core knowledge systems' that support basic intuitions about the world including objects and their motion, space, number, and time. What is the origin of these systems, and what is their nature? Although often regarded as separate, domain-specific modules, evidence for similar abilities across many nonhuman species suggests that core systems might be integrated, consistent with views of modularity in evolutionarydevelopmental biology. Here we propose that core knowledge systems are based on an ability to form representations of the environment with algebraic structure - that is, on implicit computation. Algebraic groups encode symmetries, with computation inherent in the structure - a view that complements an understanding of computation as action or function. Our proposal is related to previous applications of group theory in perception and computational-representational accounts of learning (Gallistel, 1990), but suggests for the 
first time a common basis for core knowledge across humans and nonhumans. Implicit computation can be studied experimentally with an 'artificial algebra' task in which adults learn to respond based on arithmetic combinations of stimulus magnitudes, by feedback and without explicit instruction. Asking why organisms have a capacity for implicit computation suggests two possibilities: Either the geometric invariants of the world have been internalized in perceptual systems by natural selection (Shepard, 1994), or mathematical structure is intrinsic to the mind. Understood more broadly in a framework offered by Penrose (2004), implicit computation is a linchpin with potential to unlock some of the most fundamental questions about relationships between the mind, mathematics, and the world.

Keywords: core knowledge systems, object permanence, object perception, spatial reorientation, spatial navigation, number sense, numerical cognition, comparative cognition, perception, algebra 


\section{Implicit Computation and the Origins of Knowledge}

\section{Introduction}

Where does our knowledge of the world come from? This question has been at the heart of the Western philosophical tradition since the ancient Greeks, pivoting in the $17^{\text {th }}$ century on a controversy between the doctrines of rationalism and empiricism. Rationalist philosophers such as Descartes and Leibniz held that reason (and therefore the mind) was the source of true knowledge, whereas empiricists like Hume and Locke argued that all knowledge was acquired through sense experience. In Critique of Pure Reason, Kant (1781) attempted to reconcile and transcend these opposing views by showing how a priori intuitions about space and time, alongside concepts such as objecthood and causality, provided an innate scaffolding through which sensory experience was necessarily structured. Kant's work is often regarded as the founding of modern philosophy (Strawson, 1966), and is claimed by some to have laid important groundwork for the development of modern psychology (Leary, 1982).

The dialectic between rationalist (or nativist) and empiricist approaches has been recapitulated in cognitive science over the last 40 years. Computationalist theories such as Fodor's (1975) 'language of thought' hypothesis and related proposals (e.g., Fodor, 1980; Fodor \& Pylyshyn, 1988; Pinker, 2003; Putnam, 1967) explained cognition as processing of symbolic mental representations according to innate syntactic rules or modules, whereas connectionist accounts used artificial neural networks that learned by experience to model cognition (Kruschke, 1992; Rumelhart, McClelland, et al., 1986; Norris, 1994; Quinn \& 
Johnson, 2000; Verguts \& Fias, 2005). Research in developmental science has begun to reveal scaffolding reminiscent of Kant: Studies using preferential-looking tasks have shown that infants have 'core knowledge systems' that support intuitions about the physical world such as objects and motion, space, and number (Feigenson, Dehaene, \& Spelke, 2004; Spelke, Lee, \& Izard, 2010; Spelke, 1998; Spelke, Breinlinger, Macomber, \& Jacobson, 1992; Spelke \& Kinzler, 2007). In the last decade, hierarchical Bayesian models of cognitive development have come to the fore (Tenenbaum, Kemp, Griffiths, \& Goodman, 2011; Ullman \& Tenenbaum, 2020). According to these accounts, core knowledge systems are effectively 'start-up software', underpinning the probabilistic generative programs that enable children to build conceptual models of the world (Griffiths, Chater, Kemp, Perfors, \& Tenenbaum, 2010; Perfors, Tenenbaum, Griffiths, \& Xu, 2011; Tenenbaum et al., 2011; Ullman \& Tenenbaum, 2020).

The Bayesian approach of applying top-down models to 'reverse-engineer the mind' has been highly influential and arguably represents a kind of Kantian synthesis of nativism and empiricism (Griffiths et al., 2010). It has also had significant impact in artificial intelligence (AI), inspiring attempts to build 'machines that learn and think like people' (Lake, Ullman, Tenenbaum, \& Gershman, 2017). Neuroscience has also been influenced by Bayesian ideas (e.g., the 'free energy' principle for neural organization; Friston, 2010) and in turn, neuroscience has contributed to AI (Hassabis, Kumaran, Summerfield, \& Botvinick, 2017). The remarkable recent advances in applications of AI (e.g., Krizhevsky, Sutskever, \& Hinton, 2012; Silver et al., 2016; Silver et al., 2017) appear to confirm the validity of the computational approach to understanding intelligence enabled by a convergence between cognitive science, neuroscience and AI (Gershman, Horvitz, \& Tenenbaum, 2015). 
But key questions remain unanswered: What is the nature of core knowledge systems - the 'start-up software'? Where do they come from? Reverse-engineering the mind by computational modelling cannot help here. Evolution is the obvious answer; evidence of similar abilities has been found with nonhumans, including newly-hatched chicks in controlled rearing studies (Chiandetti, Spelke, \& Vallortigara, 2015; Chiandetti \& Vallortigara, 2008, 2010, 2011; Rugani, Fontanari, Simoni, Regolin, \& Vallortigara, 2009; Wood, 2013), confirming that these abilities are innate and do not depend on individual ontogeny. Even insects show similar capacities (Howard, Avarguès-Weber, Garcia, Greentree, \& Dyer, 2019; Srinivasan, 2010, 2015; Wystrach \& Beugnon, 2009). The brain is not a tabula rasa; it has core systems of knowledge that are evolutionarily ancient. But what is their nature?

We propose that core knowledge systems are based on a capacity to form representations of the world with algebraic structure, that is, on implicit computation. Here we describe the background and rationale for this proposal, and argue that it is a linchpin hypothesis, a key leverage point for understanding the origins of knowledge with potentially far-reaching implications for the cognitive sciences and beyond. The organization of this paper is as follows. First we review evidence for core knowledge systems and related capabilities $(\S 2)$. After providing some brief mathematical background and historical context (§3), we define implicit computation and argue that it gives the best explanation for core knowledge systems, and suggests a novel perspective of computation by the mind as structure not function $(\S 4)$. Evidence that humans are able to perform the equivalent of algebraic operations with nonsymbolic magnitudes is reviewed (§5). Asking why organisms have a capacity for 
implicit computation leads to fundamental questions about the evolution of perceptual and cognitive systems, which we call 'Empiricism vs Nativism 2.0’: Either the geometric and algebraic invariants of the external world have been internalized by evolution or mathematical structure is, at least to some extent, intrinsic to the mind and brain (§6). Finally, we frame implicit computation more broadly in the nexus of relationships between the mind, mathematics and the world (§7), and show that it offers a new perspective on the origin of mathematics, reasons for the success of artificial intelligence, and highlights the relevance of pure mathematics for cognitive science and neuroscience. It is remarkable to consider that algebraic groups and related ideas - abstract objects that took humans literally millennia to discover and reason about with symbols - might characterize the representations that organisms form of their environment, and suggests that understanding implicit computation may also provide insight into fundamental questions about the 'unreasonable effectiveness' of mathematics in the physical sciences (Wigner, 1960).

\section{Core Systems of Knowledge}

In The Construction of Reality in the Child, Piaget (1954) described the development of the 'object concept' - the belief that an object cannot exist at two points of time without also existing during the interval between them (i.e., object permanence). According to Piaget, infants did not begin to develop object permanence until about 9 months of age, based on younger infants' failure to search for objects that had been hidden. This conclusion was strongly challenged by later research using a violation-of-expectancy/preferential looking task (Baillargeon, Spelke, \& Wasserman, 1985). In Baillargeon et al.'s study, five-month old infants saw two event sequences with a box that was gradually occluded as a screen was 
raised and then lowered like a drawbridge. In the possible sequence, the screen stopped when it struck the box and then lowered, making the box visible again, whereas in the impossible sequence the screen continued all the way down as if the box had vanished, but then the box was revealed when the screen was lowered. Results showed that the infants looked longer at the impossible sequence, suggesting that they were surprised by it and therefore understood that the box had continued to exist after it was occluded by the screen.

Building on Baillargeon et al.'s (1985) results, many later studies have used violation-ofexpectation (VOE) and related methods to probe infants and young children's understanding of the world. This research has documented a range of abilities that are collectively described as 'core systems of knowledge' and support basic intuitions about the physical world objects and their motion, space, and number (Spelke, 1998; Spelke et al., 1992; Spelke \& Kinzler, 2007). Core systems for space and number are assumed to have two subsystems each (Feigenson et al., 2004; Spelke et al., 2010) Additional core systems are believed to support infants' knowledge about the social world - agents and their goal-directed actions, and psychological reasoning about mental states and inferences about what others do or do not know (see Baillargeon, Scott, \& Bian, 2016, Baillargeon et al., 2015, Spelke, Bernier, \& Skerry, 2013, for review). According to an influential view, all these core systems are separate and domain- and task-specific, but are eventually integrated as part of children's cognitive development (Spelke, 2000).

Because our focus is to understand the origin of core knowledge systems, we focus on those systems for which there is considerable evidence of generality across species, suggesting they are evolutionarily ancient. These are the systems that support adaptive behavior in the 
physical world, enabling interaction with objects, orientation and navigation in a spatial environment, and discrimination of quantity and number. Evidence for a core system that supports inferences about the social world across species is less clear. Although there has been keen interest in whether nonhumans have a capacity for social cognition, the research has been controversial (e.g., Heyes, 1998; Penn, Holyoak, \& Povinelli, 2008; Penn \& Povinelli, 2007; Povinelli \& Vonk, 2003), leading to ever-more elaborate experimental designs (Lurz \& Krachun, 2019; Lurz, Krachun, Mahovetz, Wilson, \& Hopkins, 2018). Thus we do not consider research on infants' reasoning about social cognition or causality here. However, it is important to note that these systems are presumed to make inferences based on sequences of events that occur in a temporal sequence, suggesting that time perception is a necessary ability (note that studies on object permanence also are based on event sequences). Thus below we review evidence for interval timing in infants and nonhumans, and suggest that it makes sense to consider time alongside space and number as fundamental magnitudes with respect to core knowledge systems.

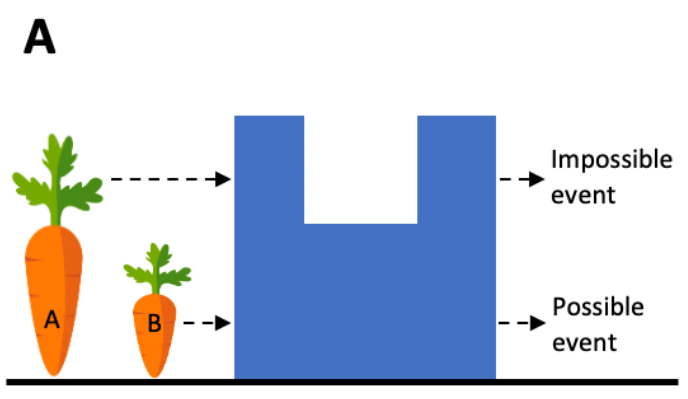

\section{C}
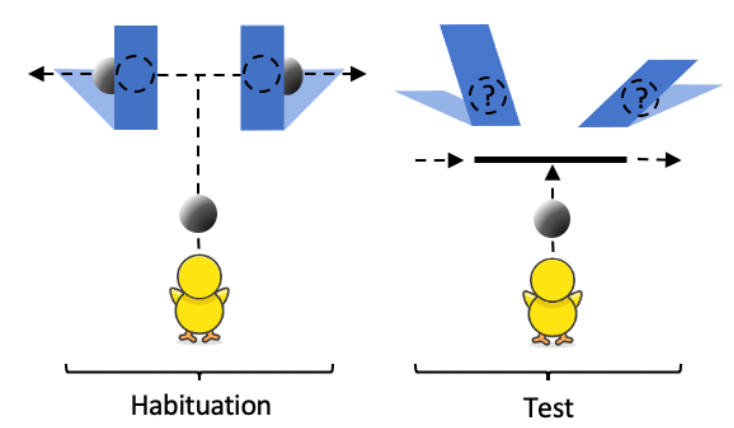

B

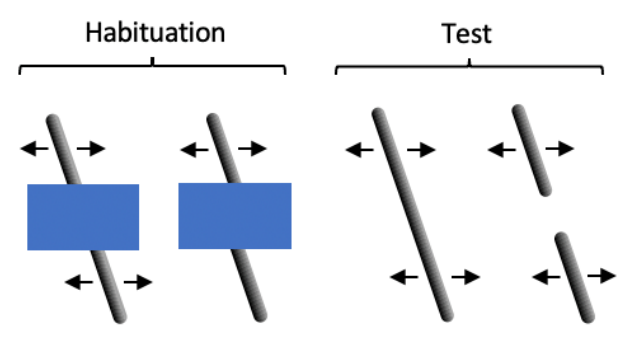

D

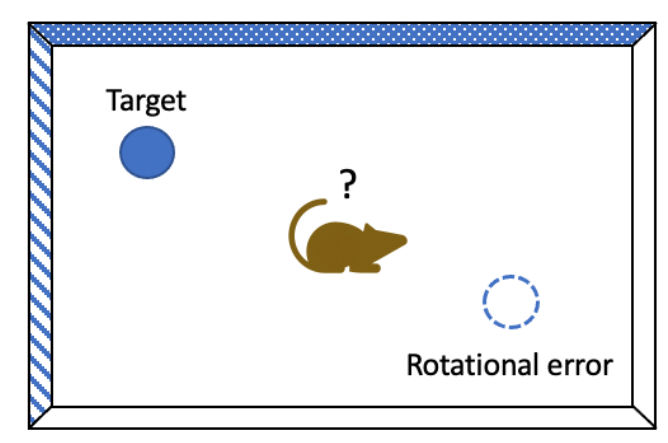


Figure 1. A. Infants that were habituated to seeing a short or tall carrot move behind a rectangular screen and then reappear looked longer during test trials with a notch in the screen with the tall carrot (impossible event; Baillargeon \& DeVos, 1991). B. Infants that saw a rod moving behind a block looked longer if the block was removed to reveal two rods (amodal completion; Kellman \& Spelke, 1983). C. Chicks saw an imprinted object move behind one of two screens and were allowed to rejoin it in habituation trials. Later the motion of the object was blocked from view and the slant of the screens was changed; chicks chose the screen that could have hidden the object (Chiandetti \& Vallortigara, 2011). D. Rats that learned to search for food in a particular corner of a rectangular box and were later disorientated and return to the box, were equally likely to search in the original corner and its rotational opposite (Cheng, 1986).

\subsection{Objects}

Baillargeon (1986) tested if 6- and 8-month old infants were able to represent stationary and moving objects that were hidden using a VOE task. Infants sat in front of an inclined ramp and a screen, and viewed an event in which the screen was raised and lowered, and then a car rolled down the ramp, passed behind the screen and emerged on the other side. After habituating to this event, they viewed a sequence in which a block was placed either behind the track (so that it would not block the car-possible event) or on the track (so that it would block the car - impossible event). Infants looked longer at the impossible event, suggesting that they were able to represent the location of the stationary box and reason whether it could block the car. Baillargeon and DeVos (1991) had 31/2 month old infants watch a short or tall toy carrot move from the left, pass behind a rectangular screen, and then appear on the right of the screen. After habituating to these events, infants saw possible and impossible test events in which the carrots passed behind a rectangular screen with a notch at the top. Infants looked longer at the impossible event with the tall carrot, which should have been partially visible as it passed by the notch (but was not; Figure 1A). 
Although Baillargeon et al.'s (1985) findings have been successfully replicated (e.g., Bremner et al., 2005; Durand \& Lécuyer, 2002), the research has generated some controversy, with claims that increased looking times for impossible events are due to 'low level' perceptual factors such as preference for novelty or familiarity (Bogartz, Shinskey, \& Schilling, 2000; Cashon \& Cohen, 2000; Houston-Price \& Nakai, 2004). However, converging evidence for infants having some capacity for object permanence comes from studies suggesting that infants perceive moving objects as unitary in the presence of an occluder (amodal completion). Kellman and Spelke (1983) showed that when four-month old infants were habituated to a rod moving behind a rectangular block, they looked longer at a fragmented compared to connected rod presented later on test trials (Figure 1B; see also Spelke, 1990). There is also evidence that infants who perceive occluded objects as unitary are more likely to perform better in tasks related to visual attention (Amso \& Johnson, 2006; Johnson, Slemmer, \& Amso, 2004). Overall, these findings suggest that principles of continuity, cohesion and persistence guide infants' interpretation of physical events (Baillargeon, 2008; Spelke, 1998; Spelke et al., 1992; Spelke, Katz, Purcell, Ehrlich, \& Breinlinger, 1994; Spelke, Kestenbaum, Simons, \& Wein, 1995), providing a core system for object perception in infants: Objects exist and move continuously in time and space (continuity), are connected and maintain their integrity (do not fragment or fuse with other objects), and retain their properties as they move.

There is considerable evidence that nonhumans possess a similar core system for object perception. Many species have shown an ability to maintain a representation of a hidden object over time, including nonhuman primates (Natale, Antinucci, Spinozzi, \& Potí, 1986), marine mammals (Singer \& Henderson, 2015), psittacine birds (Funk, 1996; Pepperberg \& Funk, 1990), lemurs (Deppe, Wright, \& Szelistowski, 2009), and domestic dogs (Fiset, 
Beaulieu, \& Landry, 2003; Miller, Rayburn-Reeves, \& Zentall, 2009) and cats (Fiset \& Doré, 2006). However perhaps the most striking evidence comes from chicks that show a lasting preference for the first image they see after hatching (imprinting). Chiandetti and Vallortigara (2011) exposed newly-hatched chicks to a novel object and allowed them to rejoin the object after it disappeared behind one of two opaque screens (Figure 1C). Later they were given a choice between screens that varied in height, slant and width, and chose the screen that was most similar to that which had previously hidden the object, suggesting they had formed a representation of the object. Wood (2013) reared chicks from birth to two weeks of life in a computer-controlled chamber equipped with a screen, and exposed them during the first week to a novel object that rotated through a 60 degree angle. During the second week, chicks recognized the object after novel transformations of its appearance, suggesting that they had developed a viewpoint-invariant representation. Recently, Wood and Wood (2021) showed that chicks were able to parse features of a novel object from its background after a single viewing (one-shot parsing) when motion cues were provided. The importance of motion cues resembles Kellman and Spelke's (1983) findings with infants, and suggests that the mechanisms underlying object individuation are similar. Overall, results of studies reviewed here suggest that a core system for objects that is innate and does not depend on individual ontogeny is found widely across species.

\subsection{Space}

The ability to move and function in an environment defined by relatively enduring boundaries and features is essential to survival for many species. Reflecting this importance, spatial cognition has long been a keen topic of research. The first systematic investigation 
was conducted by Tolman (1948), who concluded that rats navigating a variety of mazes in search of food reward formed an allocentric 'cognitive map' of their environment. Broadly speaking, research since then has concentrated on two major questions: How do moving organisms keep track of their position within an environment while moving towards a goal (i.e., spatial navigation); and what information does an organism encode about its environment, as revealed by how it regains its orientation (i.e., spatial reorientation). Perhaps because motor skills develop slowly in infants and small children, research from a core knowledge perspective has focussed more heavily on the latter question. The aim has been to discover the evolved capacities, present at birth, which allow infants to learn and reason about their spatial environment and which provide the scaffolding for later learning of geometric principles (Spelke et al., 2010).

Much of this research has used a spatial reorientation task first developed by Cheng (1986; see also Gallistel, 1990). In Cheng's study, rats were placed in an enclosed rectangular box and trained to search for food that could be hidden in one of the four corners, which were each marked by a distinctive visual pattern and odor. On each trial, after locating the food and eating a small amount, they were removed from the box for 90 seconds and then placed in the centre of an exact replica of the box with food hidden in the same location. Rats showed systematic errors in searching for the food, such that they were equally likely to search in the correct corner as well as its rotational opposite (Figure 1D). This result, suggesting that Cheng's rats reoriented based on the overall shape of the box but not the featural cues, has been replicated with young children (Hermer \& Spelke, 1996; Hermer \& Spelke, 1994; Lee \& Spelke, 2008, 2011) and a variety of nonhuman species such as chicks (Chiandetti \& Vallortigara, 2010; Lee, Spelke, \& Vallortigara, 2012), mice (Twyman, Newcombe, \& Gould, 2009), monkeys (Gouteux, Thinus-Blanc, \& Vauclair, 2001), fish 
(Lee, Ferrari, Vallortigara, \& Sovrano, 2015), and ants (Wystrach \& Beugnon, 2009).

However, adults are able to use featural cues along with geometric ones (Hermer \& Spelke, 1994), and natural language ability may facilitate cue integration (Hermer-Vazquez, Spelke, \& Katsnelson, 1999), suggesting that there might be two systems, one for geometric and another for featural cues (Lee, Shusterman, \& Spelke, 2006; Lee \& Spelke, 2010). Spelke et al. (2010) have also proposed that there may be two core systems that support later learning of geometric principles: One system that applies to the large-scale shape of an environment and is sensitive to distance and sense (left-right) relations, and a second system that applies to small-scale forms, is sensitive to angle, and allows young children to categorize objects by their shape and distinctive characteristics (Izard \& Spelke, 2009).

Theories of performance in the spatial reorientation task include Cheng's (1986) original account that there was a purely geometric module for spatial processing, that subjects remember different views of the environment and match them (Stürzl, Cheung, Cheng, \& Zeil, 2008), associative learning (Miller \& Shettleworth, 2007), and adaptive combination theory (Newcombe \& Huttenlocher, 2007; Y. Xu, Regier, \& Newcombe, 2017), although available data do not clearly distinguish between these accounts (see Cheng \& Newcombe, 2005, Spelke et al., 2010, Tommasi, Chiandetti, Pecchia, Sovrano, \& Vallortigara, 2012, for review). Nevertheless, there is substantial converging evidence to suggest that boundaries play a key role in the representations that organisms form of their environment (Lee, 2017).

\subsection{Number}


A world of objects will necessarily have collections of objects, and so an ability to discriminate and behave adaptively with respect to quantity of food items, predators, potential mates, and so forth is essential for survival. Research has shown that a wide range of species have a system that supports basic intuitions about quantity, known as 'number sense' (see (Dehaene, 2011, Leibovich, Katzin, Harel, \& Henik, 2017, Lorenzi, Perrino, \& Vallortigara, 2021, for review). There is evidence for two separate subsystems in number sense. One is known as the 'object tracking system' (OTS) or 'subitizing' (Mandler \& Shebo, 1982) and supports a capacity to quickly and accurately recognize small numbers of objects (e.g., up to 3 or 4 items; Figure 2A), while the 'approximate number system' (ANS) is relatively imprecise but allows the discrimination of larger numerosities (Feigenson et al., 2004). The ANS is characterized by a Weber's law relation in which discriminability depends on the numerosity ratio, whereas the OTS does not show a similar ratio effect (Figure 2B).

Research with infants has documented both subsystems of number sense. Feigenson, Carey, and Hauser (2002) used a choice task in which 10- and 12-month old infants saw crackers placed one at a time into two containers, and then were allowed to choose a container by crawling toward it. Infants were able reliably to choose the larger quantity with comparisons of 1 vs 2 and 2 vs 3, but failed with 3 vs 4, 2 vs 4 and 3 vs 6 , suggesting that they could recognize up to three objects, consistent with the OTS (see also Starkey \& Cooper, 1980). Using a violation-of-expectation (VOE) task, Xu and Spelke (2000) found that six-month old infants could discriminate between 8 and 16 objects (solid round black dots on white paper), but not between 8 and 12, suggesting a ratio effect as predicted by the ANS (see also Xu, 2003; Xu, Spelke, \& Goddard, 2005). 
A
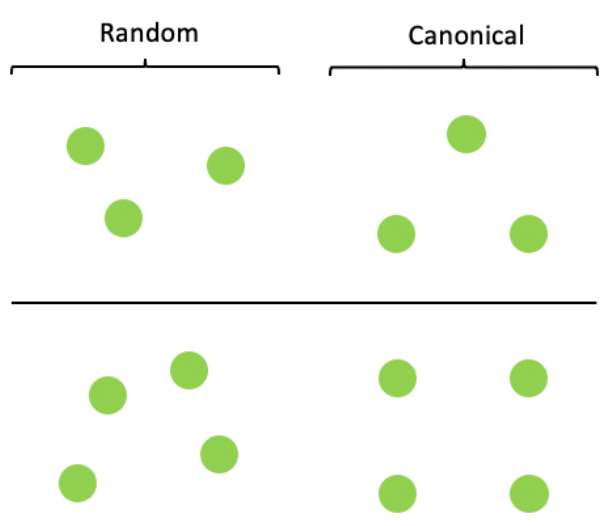

C

1. Object placed in case

2. Screen comes up

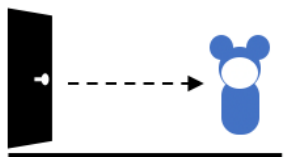

B
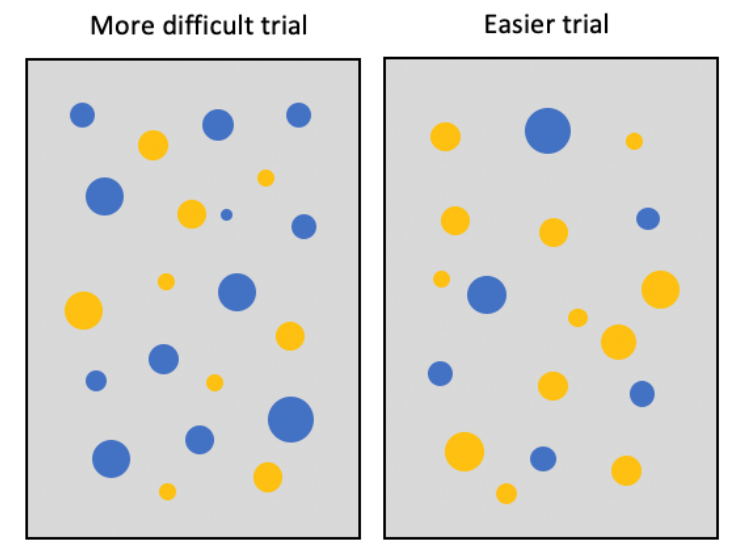

4. Screen drops

3. Second object added
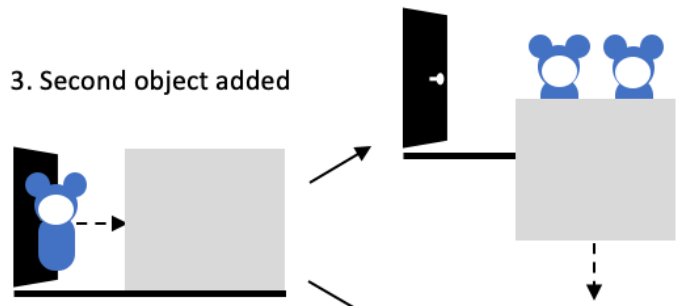

Possible outcome

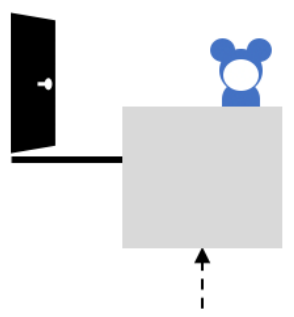

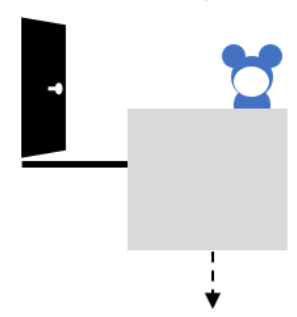

Impossible outcome

Figure 2. A. Stimuli used in research on subitizing, in which participants are asked to identify rapidly the number of objects (here shown in both random and canonical configurations; Mandler \& Shebo, 1982). B. Typical trials on a numerosity discrimination task, where participants are asked to identify whether blue or yellow dots are more numerous (left: difficult trial, 12B 9Y; right: easier trial, $9 Y$ 6B). C. Perceptual addition task developed by Wynn (1992). Infants saw a puppet placed in a case, and after a screen was raised, another puppet was moved behind the screen. Later when the screen dropped, infants looked longer at the impossible (' $1+1=1$ ') than possible (' $1+1=2$ ') outcome.

Because number, a discrete magnitude, is necessarily confounded with continuous magnitudes in the dot discrimination tasks typically used to assess numerosity (e.g., surface area, density, convex hull), there has been much debate about whether participants are actually responding on the basis of number and not continuous magnitudes (Gebuis \& 
Reynvoet, 2012; Leibovich et al., 2017). In an EEG study, Park, DeWind, Woldorff and Brannon (2016) showed that evoked potentials in adults were better predicted by number than continuous variables (see also DeWind, Park, Woldorff, \& Brannon, 2019). One possibility is that core system corresponding to number sense may represent both discrete and continuous magnitudes.

Number sense is assumed to provide a scaffolding for the early learning of symbolic mathematics (Feigenson, Libertus, \& Halberda, 2013; Starr, Libertus, \& Brannon, 2013), which predicts later success in both education (Duncan et al., 2007; Geary, Hoard, Nugent, \& Bailey, 2012) and employment outcomes (Rivera-Batiz, 1992). Halberda, Mazzocco, and Feigenson (2008) found that 14-year-olds' accuracy on a nonsymbolic numerical discrimination task retrospectively predicted mathematics achievement from kindergarten, and meta-analyses of subsequent studies have confirmed a positive correlation $(r=.20)$ between ANS acuity and mathematics learning (Chen \& Li, 2014; Fazio, Bailey, Thompson, \& Siegler, 2014).

Studies have also shown that infants can perform the equivalent of arithmetic operations with small numbers of objects. In a classic study, Wynn (1992) had five-month old infants watch a stage in which a hand emerged from the side and placed a toy (Figure 2C). A screen was raised, and the hand placed a second toy behind the screen (' $1+1=2$ '). On some trials, one toy was then removed via a trap door unseen by the infants, and when the screen was lowered, infants looked longer at the single toy, suggesting they had expected to see two toys. Other trials tested the equivalent of subtraction, and found that infants looked longer if when after having seen two toys on the stage and one removed, that there were two toys remaining 
when the screen was lifted ('2 $-1=1$ '). Wynn's (1992) findings have led to many follow-up studies and replications (e.g., Cohen \& Marks, 2002; Simon, Hespos, \& Rochat, 1995) and although there has been controversy about whether infants' responding is influenced by nonnumerical cues such as familiarity, area, or contour length (Mix, Huttenlocher, \& Levine, 2002), a recent meta-analysis concluded that the basic effect was reliable (Christodoulou, Lac, \& Moore, 2017). Importantly, studies with nonhumans such as rhesus monkeys (Hauser, MacNeilage, \& Ware, 1996), newly-hatched chicks (Rugani et al., 2009) and honeybees (Howard et al., 2019) have found similar results, confirming that the ability to perform the equivalent of arithmetic with small numbers of objects in perceptual tasks has wide generality across species.

\subsection{Time}

Time is a fundamental dimension of the physical world, in which regularities like the daynight cycle and seasonal variation are defined, as well as short-term phenomena such as the duration of foraging visits or homeward travel. Thus it is not surprising that timing and temporal cognition have been studied and documented in many species. Research suggests that organisms have evolved three major subsystems to deal with temporal regularities on different scales: Circadian timing for diurnal variation, millisecond timing for precise motor skills, and interval timing for behavioral decision making and coordination over short to intermediate durations (Buhusi \& Meck, 2005). Of these, interval timing has been the most intensively studied. A key characteristic of interval timing is Weber's law - the error in estimation increases linearly with the timed interval, so that discriminability depends on the duration ratio, similar to the ANS for numerosity (for reviews on timing research, see 
Grondin, 2001, 2010; Kononowicz, Van Rijn, \& Meck, 2018). There is also evidence of rapid and precise temporal learning by nonhumans (rats, pigeons) with procedures in which intervals to be timed are changed frequently (Higa, 1997; Higa, Wynne, \& Staddon, 1991; Kyonka \& Grace, 2007).

Research with infants has confirmed the basic aspects of interval timing noted above. VanMarle and Wynn (2006) had six-month old infants watch a puppet equipped with an auditory speaker that could emit a tone when the puppet moved. Using a VOE task, infants could discriminate between tones in a $2: 1$ ratio ( $4 \mathrm{~s}$ vs $2 \mathrm{~s}$; or $1 \mathrm{~s}$ vs $.5 \mathrm{~s}$ ), but not a 1.5:1 ratio ( $4.5 \mathrm{~s}$ vs $3 \mathrm{~s}$; or $1 \mathrm{~s}$ vs $.67 \mathrm{~s})$, demonstrating a Weber's law result similar to numerosity (Lipton \& Spelke, 2003; Xu \& Spelke, 2000; Xu et al., 2005). Addyman, Rocha, and Mareschal (2014) found evidence for scalar variability in timing of four-month old infants using an eye-tracking paradigm. Other studies have used heart-rate (Colombo \& Richman, 2002) and EEG (Brannon, Roussel, Meck, \& Woldorff, 2004) measures to confirm accurate timing by infants. Overall, these results suggests that infants have a system for estimating temporal durations as continuous magnitudes that is accurate and characterized by a Weber's law property (i.e., scalar variability), similar to nonhumans.

\subsection{Computationally-Complex Behavior}

The research reviewed in $\$ 2.1-2.4$ suggests that organisms are able to represent physical variables such as distance, length, angle, number and time as continuous magnitudes. But there are phenomena that seem also to require the equivalent of arithmetic or algebraic operations performed on represented magnitudes. Spatial navigation by path integration is a 
good example. Although humans (and other organisms) are often able to use allocentric maps or beacons to navigate (Ekstrom \& Isham, 2017), many species can also employ an egocentric strategy, path integration, for navigation. As Figure 3 illustrates, a foraging honeybee might make a convoluted outward journey from the hive until discovering food, then return by most direct route (Riley, Greggers, Smith, Reynolds, \& Menzel, 2005). Path integration appears to be a universal method for navigation, having been found in species as diverse as insects (e.g., ants and honeybees; Cheng, Narendra, Sommer, \& Wehner, 2009; Collett \& Collett, 2000; Collett, 2019; Müller \& Wehner, 1988; Riley et al., 2005), crustaceans (Murakami, Tomaru, \& Gunji, 2017), and mammals (including humans (Loomis et al., 1993; Wang \& Spelke, 2002; see Etienne \& Jeffery, 2004, for review).

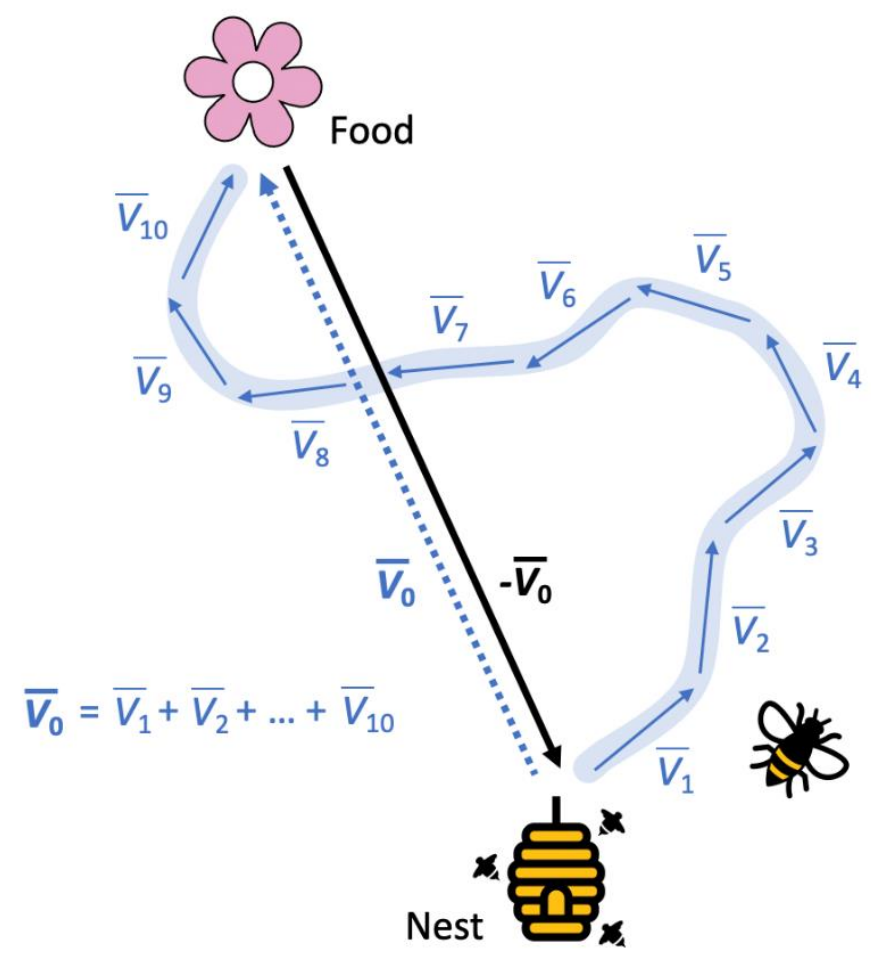

Figure 3. Spatial navigation by path integration. Foraging honeybees are able to keep track of their location relative to their nest such that after finding food, they are able to return by most direct route. 
We have described navigation by path integration as 'computationally-complex behavior', as one-shot foraging journeys of individual organisms appear to require the equivalent of algebraic computation (Grace, Carvell, et al., 2020). Theoretical accounts of path integration include Gallistel's computational-representational theory, which assumes that organisms represent environmental variables such as angle with respect to the sun and distance travelled as vectors of real numbers stored in an engram, and proposes that the mechanism of molecular coding should be a prime focus of research (Gallistel, 2017, 2018; Langille \& Gallistel, 2020). Neural network models of path integration have also been proposed, taking into account the neuroanatomy of the insect brain (e.g., Stone et al., 2017). However, all accounts assume that at a behavioral (functional) level, individual organisms are able to integrate information about distance and angle when navigating. The simplest description of this integration is that organisms are able to perform the equivalent of algebraic operations on represented magnitudes, consistent with our definition of 'computationally complex behavior' (Grace et al., 2020).

It is interesting to note that robotics have been influenced by research on insect navigation (Webb, 2019). Mobile robots are able to develop a map of their local environment while tracking their location in real-time using a technique called SLAM (Simultaneous Localization and Mapping; Bailey \& Durrant-Whyte, 2006; Durrant-Whyte \& Bailey, 2006). SLAM defines navigation as a computational problem, and combines path integration and landmark detection and mapping. Current implementations use joint probabilistic estimates of location and landmarks, updated by recursive Bayesian modelling, to enable real-time applications such as drones flying in an industrial environment (Mur-Artal \& Tardós, 2017). Thus, robotics research shows that solving navigational problems similar to those faced by flying insects requires sophisticated computation. 
There are many other examples of adaptive behavior that appear to require the equivalent of algebraic computation. An extensive research literature on associative learning and conditioning shows that organisms are able to learn the predictive relationships between stimuli (both neutral and biologically-relevant stimuli such as food rewards) and can respond adaptively based on rates and probabilities of reward depending on prior stimuli (Gallistel \& Gibbon, 2000; Miller \& Grace, 2003). Research on behavioral decision making shows that animals can match their allocation of responding between alternatives to the proportion of reward received from them (Gallistel et al., 2007; Herrnstein, 1961), and combine information about reward characteristics additively (e.g., rate, magnitude, delay, probability; Baum \& Rachlin, 1969; Cording, McLean, \& Grace, 2011; Kyonka \& Grace, 2008). Another example of behavior that appears to require computation is optimal cue integration - where multiple cues are combined inversely proportional to their variance, consistent with Bayesian optimality - which has been found in species from ants to humans (Cheng, Shettleworth, Huttenlocher, \& Rieser, 2007; Ernst \& Banks, 2002; Wystrach, Mangan, \& Webb, 2015). Statistical learning of auditory and visual patterns, documented in infants and newly-hatched chicks (Aslin \& Newport, 2012; Saffran, Aslin, \& Newport, 1996; Santolin, Rosa-Salva, Vallortigara, \& Regolin, 2016; Santolin \& Saffran, 2018), is another. All these examples suggest that perceptual and cognitive systems have evolved to enable the equivalent of algebraic computation with represented environmental magnitudes.

2.6 Core Systems of Knowledge - Summary 
Research in developmental science has shown that the brain is not a tabula rasa at birth, but that infants have a suite of 'start-up software' or core knowledge systems that facilitate the developing child's interaction with the physical and social world (Spelke \& Kinzler, 2007; Ullman \& Tenenbaum, 2020). Spelke (2000) has noted that these systems are domain- and task-specific, in that each system represents only a limited subset of the information that infants perceive and functions to solve a specific set of problems, and encapsulated in that each system operates independently of the others. However, there is compelling evidence from comparative studies that these core systems are shared widely across the animal kingdom. Because systems which support intuitions about objects and motion, space, quantity and time are found in species with neural architectures as diverse as those of honeybees and humans, the implication is that these systems have either evolved independently at multiple times (i.e., convergent evolution), or are homologous and share a common origin or ancestor that is evolutionarily ancient.

Core systems of space and number, along with the capacity for timing, are similar in that they represent magnitudes which can be described or modelled as real numbers. This similarity has been the basis of proposals for a generalized magnitude system of cortical processing of space, time and number (Walsh, 2003, 2015), and there is recent evidence that topographically organized brain areas for these magnitudes in association cortex largely overlap (Harvey, Dumoulin, Fracasso, \& Paul, 2020). Neonates $(0-3 d)$ have also been found to react when spatial extent, duration and numerosity changed in the same way (either increase or decrease), suggesting a common representation of magnitude (de Hevia, Izard, Coubart, Spelke, \& Streri, 2014). The ability of core knowledge systems to perform the equivalent of operations on represented magnitudes, as evidenced by path integration and other examples of computationally-complex behavior, suggests that magnitudes have 
algebraic properties. An implication of these similarities is that mathematical concepts may be helpful for our understanding of core knowledge systems. Although the object system may appear to be different, we argue below that mathematical concepts are relevant here as well.

The next section sketches a (very) brief overview of the history of mathematics and algebra. Historical context is important because from a modern vantage point, it is easy to assume that the relevant mathematics for core knowledge systems is what we learn in school - arithmetic, geometry, algebra. This assumption is likely due in part to the research linking core knowledge systems with mathematics education and achievement (Feigenson et al., 2013) and learning disorders such as dyscalculia (Wilson \& Dehaene, 2007). There also may be a tendency to regard the 'standard' mathematics we learn as a fixed and established body of knowledge, rather than as one point in a long progression that began thousands of years ago and continues to the present day. But core knowledge systems are evolutionarily ancient, unlike the human endeavour of mathematics. The history of mathematics (Figure 4) provides an important context for thinking about how mathematical concepts might be relevant for core knowledge systems.

\section{Algebra and the History of Mathematics}

The earliest mathematical text dates to approximately 5000 years ago in Mesopotamia (Neugebauer, 1969). Cuneiform tablets preserve details of calculations for purposes of taxation, division of resources and other practical problems, using a sexagesimal (base-60) numerical system developed by Sumerian and Babylonian civilizations (Derbyshire, 2006). 
Mathematics was first taught as a discipline by the Greeks about two millennia later, with schools associated with Pythagoras (500 BCE) and Euclid (300 BCE) responsible for fundamental advances in geometry and mathematical rigor. Mathematics developed independently in China with many similar results as the Greeks (e.g., the Pythagorean theorem), but the most influential text (The Nine Chapters on the Mathematical Arts, roughly contemporaneous with Euclid's Elements) was unknown in Europe until the $19^{\text {th }}$ century (Shen, Crossley, Lun, \& Liu, 1999). Indian mathematicians invented the decimal place system including zero as a digit and used negative numbers around from 400 to 1200 AD. The golden age of Islamic mathematics built on works of Greek and Indian mathematicians, with its most famous exponent, Muhammad ibn Musa al-Khwarizmi writing the first treatise on algebra (in Arabic, al-jabr, meaning 'completion or reunion of broken parts'). AlKhwarizmi's work was translated into Latin in the $12^{\text {th }}$ century, as was the Elements, and influenced mathematicians in medieval Europe (Hodgkin, 2005).

With the Italian renaissance in the $15^{\text {th }}$ century, mathematical innovation shifted to Europe where expanding trade meant demand for bookkeeping and accounting skills. Pacioli's Summa Arithmetica (1494) introduced the standard symbols for plus and minus, Cardano's Ars Magna published solutions for cubic and quartic polynomial equations, and Bombelli's L'Algebra (1572) proposed imaginary quantities to express roots of cubic equations (Derbyshire, 2006). In the $17^{\text {th }}$ century, Descartes and Fermat independently developed a synthesis of algebra and geometry (i.e., analytic geometry) including the $x-y$ coordinate system that remains a foundation of mathematics education today. 


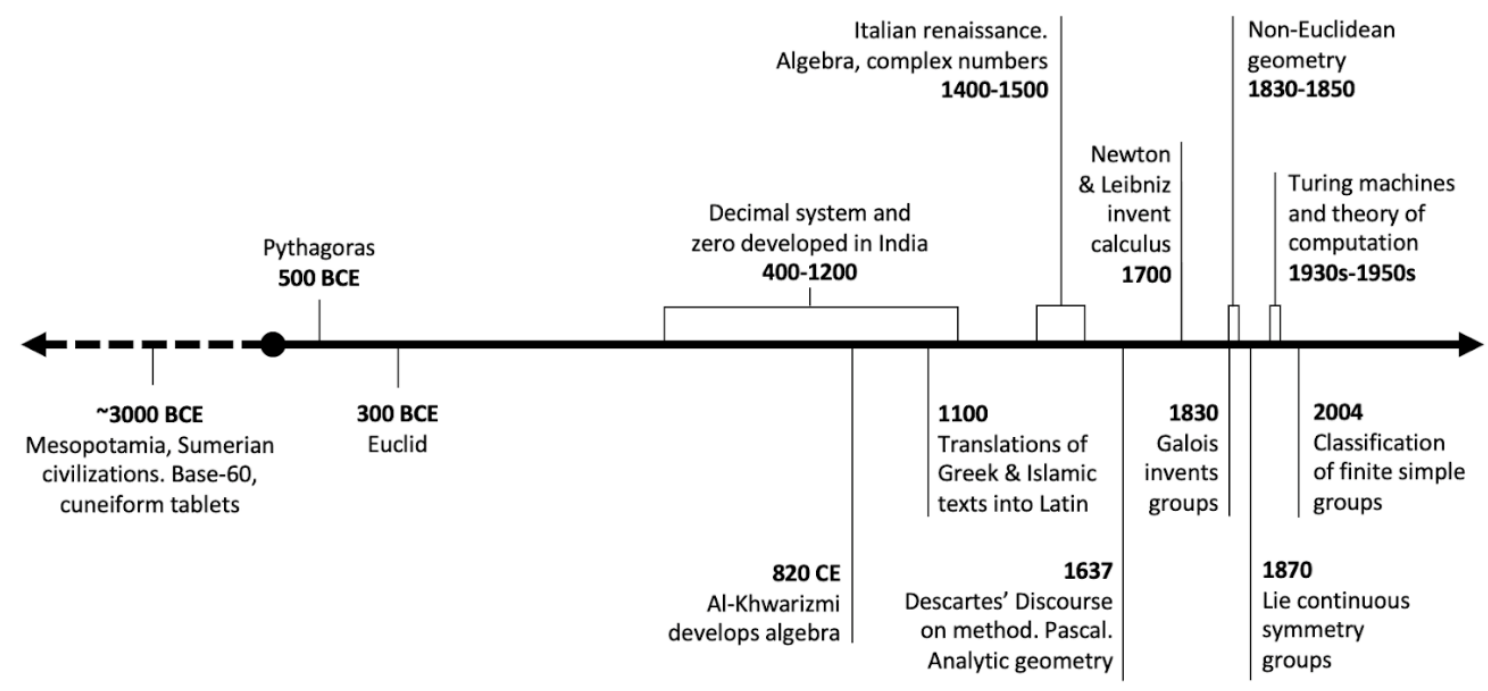

Figure 4. Timeline of the history of mathematics (with particular focus on algebra and geometry).

Mathematics in the $19^{\text {th }}$ century showed an increasing tendency towards abstraction. NonEuclidean geometries (later important for Einstein's general relativity) were invented by Bolyai, Lobachevsky and Riemann. Attempts to find general solutions to polynomial equations led Galois in the 1830s to define an algebraic group (see below), which shifted focus from calculation to underlying structure and identified symmetry as a unifying concept. Boole (1854) proposed a binary algebra that served to unify mathematic and logic, and the Norwegian mathematician Sophus Lie developed a theory of continuous symmetry groups in the 1870s, that later was essential in the development of quantum mechanics (Hawkins, 2012). In the $20^{\text {th }}$ century, Church and Turing formalized notions of computability and laid the conceptual foundations for digital computers. In turn, computers have accelerated developments in pure mathematics, such as the classification of all finite simple algebraic groups including the 'monster' (the largest sporadic simple group, of order $\sim 10^{54}$ ) - related to mathematical physics (string theory) by the 'monstrous moonshine' conjecture proven by 
Borcherds in 1982 - and the Langlands program which promises a grand unification of mathematics (Frenkel, 2013).

This brief history shows that mathematics has progressed steadily since ancient times, with the pace of innovation accelerating during the renaissance and then again in recent decades with the advent of computers. Note that progress for mathematics is unlike the physical sciences where new knowledge replaces past knowledge, so the latter is no longer regarded as fundamentally 'true' (e.g., Einstein's theory of general relativity replaced Newton's theory). By contrast, in mathematics, established knowledge remains 'true' but is understood at deeper levels of abstraction. The facts of arithmetic are still facts even if we regard the integers under addition as an algebraic group. An implication is that we do not know what level of mathematical abstraction is right for understanding for core knowledge systems. By 'right', we mean the level that most closely corresponds to the brain and cognitive function that is the proximate cause of behavior. For example, were infants in Wynn's (1992) study cognitively representing numbers and the operations of addition and subtraction (as Wynn claimed), or is the representation best described at another level of abstraction? A major point of our paper is that the level of abstraction should not be based on mathematical familiarity but rather consistency and explanatory coherence for core knowledge phenomena in general (Thagard, 1989).

Of the mathematical advances noted above, the algebraic group is one of the most important (perhaps the most important), because it shifts the focus of algebra from calculation to understanding structure. Algebraic groups generalize the intuitions underlying arithmetic. Addition over the integers satisfies the definition of a group, but there are many other groups. 
Groups encode symmetries, and algebraic group theory is the study of symmetry in all its forms and varieties. Because it is central to our argument, we give the formal definition of a group here, followed by an example:

A group is a pair $(G, \circ)$ where $G$ is a non-empty set and $\circ$ is a binary operation on $G$. A binary operation on a non-empty set $X$ is a map from $X^{2}$ to $X$; that is, a function taking ordered pairs from $X$ as inputs and returning elements of $X$ as outputs. The pair $(G, \circ)$ is a group provided the following three axioms are met.

- Associativity: For each $a, b, c$ in $G, a \circ(b \circ c)=(a \circ b) \circ c$ holds; in symbols,

$$
\forall a \forall b \forall c(a \circ(b \circ c)=(a \circ b) \circ c) .
$$

- Identity: There exists $e$ in $G$ such that for each $a$ in $G, a \circ e=e \circ a=a$ holds; in symbols,

$$
\exists e \forall a(a \circ e=e \circ a=a) .
$$

The element $e$ is the identity element.

- Inverse: For each $a$ in $G$ there exists $b$ in $G$ such that $a \circ b=b \circ a=e$ holds; in symbols,

$$
\forall a \exists b(a \circ b=b \circ a=e) .
$$

The element $b$ is the inverse of $a$.

If, in addition to the associativity, identity and inverse axioms, the binary operation $\circ$ is such that $a \circ b=b \circ a$ holds for each $a$ and $b$ in $G$, then $(G, \circ)$ is a commutative group.

The integers under addition $(\mathbb{Z},+)$ provide an example of a commutative group. The formal definition of an algebraic group effectively generalizes the intuitions underlying addition, 
because other pairs $(G, \circ)$ than the integers under addition that also satisfy the axioms can be studied as groups.

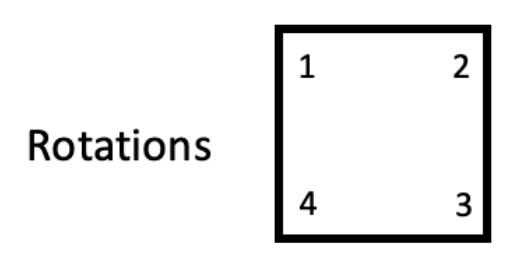

$\mathrm{R}_{0}$

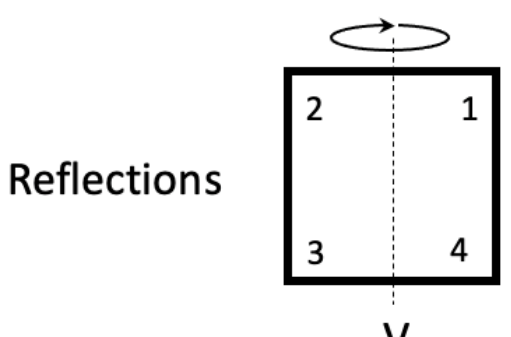

V

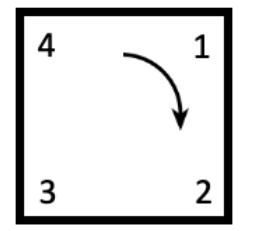

$R_{90}$

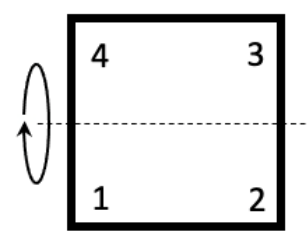

$\mathrm{H}$

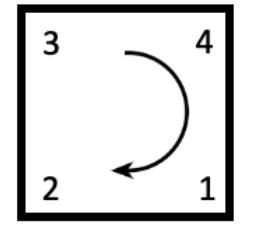

$\mathrm{R}_{180}$

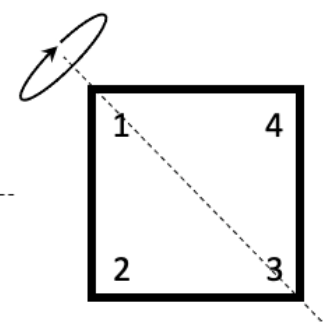

$\mathrm{D}_{1}$

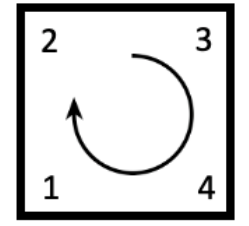

$R_{270}$

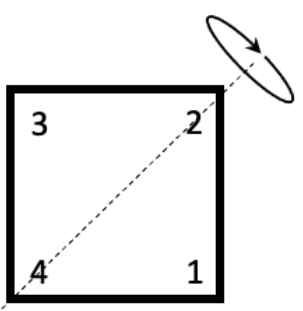

$\mathrm{D}_{2}$

Figure 5. Group of symmetries of the square. Starting from the upper left square, with vertices marked clockwise 1 through 4 from the upper left corner, various configurations are possible when the square is rotated or reflected in different ways. If these rotations and reflections are the elements of a set $G$, and an operation $\circ$ is defined as performing two rotations or reflections in succession, the pair $(G, \circ)$ is an algebraic group.

An example of a group is the 'symmetries of the square' (also known as the dihedral group of order 8). Imagine a cardboard square oriented in parallel with an $x-y$ axis, as shown in Figure 5. The elements of $G$ are the possible rigid motions of the square in three-dimensional space, which include clockwise rotations of 90,180 and 270 degrees about the origin $\left(r_{1}, r_{2}, r_{3}\right)$, reflections along the horizontal and vertical axis ( $h$ and $v)$, and reflections along the two diagonals formed by a 45 degree rotation of the horizontal and vertical axes $\left(d_{1}, d_{2}\right)$. There is also an identity motion, $e$, in which the square remains fixed. If the corners are numbered 12-3-4 prior to a motion (starting from the upper left and moving clockwise around the square), we can specify the location of the square after each motion by noting where the numbered corners end up: $e$ [1-2-3-4] $r_{1}$ [4-1-2-3], $r_{2}$ [3-4-1-2], $r_{3}$ [2-3-1-4], $h$ [4-3-1-2], $v$ [2-1-3-4], $d_{1}$ [1-4-3-2], $d_{2}$ [3-2-1-4]. 
If the operation, o, is defined as composition - that is, performing two motions in sequence, then the pair $(G, \circ)$ is a group. This can be verified by examination of Table 1 , known as a 'Cayley table', which shows the results of performing the motion in the upper row first, followed by the motion in the leftmost column. The identity, inverse, and associative axioms all hold: $e$ (no change) is the identity element; each item $a$ has an inverse $b$, such that $a \circ b=$ $b \circ a=e\left(e, r_{2}, h, v, d_{1}\right.$ and $d_{2}$ are all their own inverses, such that performing each of these motions twice gives $e$, and $r_{1}$ and $r_{3}$ are inverses of each other). The associative axiom also holds, but not commutativity (this is a non-commutative or non-Abelian group).

\begin{tabular}{c|cccccccc}
$\circ$ & $e$ & $r_{1}$ & $r_{2}$ & $r_{3}$ & $h$ & $v$ & $d_{1}$ & $d_{2}$ \\
\hline$E$ & $e$ & $r_{1}$ & $r_{2}$ & $r_{3}$ & $h$ & $v$ & $d_{1}$ & $d_{2}$ \\
$r_{1}$ & $r_{1}$ & $r_{2}$ & $r_{3}$ & $e$ & $d_{1}$ & $d_{2}$ & $v$ & $h$ \\
$r_{2}$ & $r_{2}$ & $r_{3}$ & $e$ & $r_{1}$ & $v$ & $h$ & $d_{2}$ & $d_{1}$ \\
$r_{3}$ & $r_{3}$ & $e$ & $r_{1}$ & $r_{2}$ & $d_{2}$ & $d_{1}$ & $h$ & $v$ \\
$h$ & $h$ & $d_{2}$ & $v$ & $d_{1}$ & $e$ & $r_{2}$ & $r_{3}$ & $r_{1}$ \\
$v$ & $v$ & $d_{1}$ & $h$ & $d_{2}$ & $r_{2}$ & $e$ & $r_{1}$ & $r_{3}$ \\
$d_{1}$ & $d_{1}$ & $h$ & $d_{2}$ & $v$ & $r_{1}$ & $r_{3}$ & $e$ & $r_{2}$ \\
$d_{2}$ & $d_{2}$ & $v$ & $d_{1}$ & $h$ & $r_{3}$ & $r_{1}$ & $r_{2}$ & $e$
\end{tabular}

Table 1. Cayley table for symmetry of square group. Each entry shows the resulting position of vertices of the square starting from $\{1,2,3,4\}$ when the operation in first row is followed by the operation in the first column.

Why do the rotations of the square satisfy the group axioms? The reason is that square has symmetries, so that it can be transformed in different ways without affecting its structure. The abstract definition of an algebraic group shows us that reason arithmetic 'works' is because of symmetries in how integers and the operation of addition is defined. There is one other important distinction that should be noted. The action of a group is how the operation 
changes the elements in $G$, so that we say that the group of symmetries of the square acts upon the set of possible orientations of the square (Mac Lane, 1986). The abstract definition of groups thus allows us to distinguish naturally between its structure (in terms of symmetries) and function (in terms of its effect on the elements in $G$ ).

\begin{abstract}
algebra builds on the basic concept of a group to generate more complex mathematical objects (Burton, 1988). For example, two commutative groups, $(G,+)$ and $(G, \circ)$ that are defined over the same set and connected by a distributive property, $a \circ$ $(b+c)=a \circ b+a \circ c$, comprise an algebraic field. A prototypical example of a field is the real (or rational) numbers under addition and multiplication, so fields generalize intuitions underlying basic arithmetic. Fields are used extensively in physics, as they define the scalars for vector spaces.
\end{abstract}

\title{
4. Implicit Computation and Core Knowledge Systems
}

We now return to the question posed in the Introduction: What is the nature of core knowledge systems? According to an influential view, they are domain-specific (each applies to a limited range of phenomena), task-specific (each solves a particular set of problems), and encapsulated (each system operates independently of the others; Spelke, 2000). These are the characteristics of modular cognitive systems as originally defined by Fodor (1983), and a theoretical challenge has been to explain how a unified cognitive system in humans can emerge from separate core knowledge modules. One solution has been dualprocess accounts of cognition (Evans, 2003), which assume that humans have a higher-order 
capacity for relational thinking or 'supermodule' that builds upon and integrates the lowerlevel representations of core knowledge systems (Karmiloff-Smith, 1994; Penn et al., 2008). According to this view, integration of core knowledge representations is due to humans' unique ability for abstract and relational reasoning, which explains the apparent discontinuity between human and nonhuman minds ('Darwin's mistake'; Penn et al., 2008).

But from the perspective of modern evolutionary-developmental biology, we might anticipate that core knowledge systems in nonhumans are integrated even if modular (Shettleworth, 2012; Ploeger \& Galis, 2011). Modularity is an essential concept to describe heterogeneity in biological systems (West-Eberhard, 2003), but there are different kinds of modularity (Wagner, Pavlicev, \& Cheverud, 2007) and encapsulation is not necessary (although note that Fodor's (1983) emphasis on encapsulation has been controversial in cognitive science, see Barrett \& Kurzban, 2006). Modules can be organized hierarchically and interdependently, and vary in terms of integration both within and between modules. Thus there are good reasons to expect that core knowledge systems - which act as a kind of interface between the organism's perceptual apparatus and the physical world, producing representations of external stimuli to guide adaptive behavior and action - might be connected in some way that enhanced integration across the systems (Figure 6). It is reasonable to expect that integration would be found at the representational level, without excluding also the possibility for integration at other levels as well (e.g., genetic, neural).

How might this integration be accomplished? Assuming that the representations produced by core knowledge systems share a common factor or basis, what could that be? We can use abductive reasoning (i.e., inference to the best explanation) to hypothesize the most likely 
common factor (Haig, 2018; Lipton, 2003). We propose that core knowledge systems share a capacity for creating representations of the world with algebraic structure - specifically, a structure that can be described by algebraic groups and related mathematical objects. Because algebraic groups constitute different types of symmetry, our proposal can be stated alternatively that core knowledge systems are related because they produce representations of the world that are characterized by symmetries. This capacity can be called implicit computation, because if a representation has the structure of an algebraic group, then computation - the action of the group on its elements (see §3) - would be inherent or implicit in it.

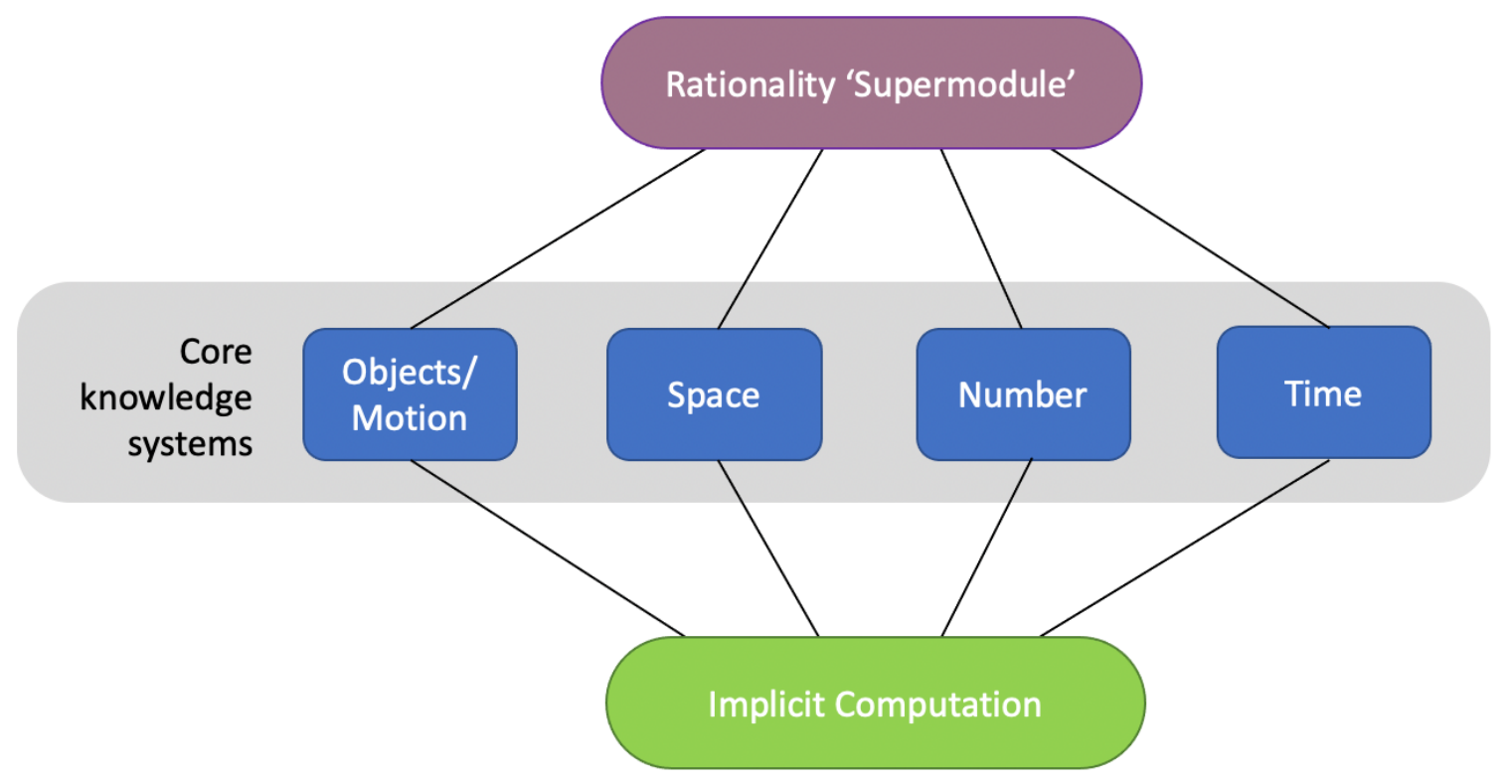

Figure 6. Illustration of how core knowledge systems for objects and their motion, space, time and number, which are assumed to be coordinated by cognitive development, might also be connected and integrated by a shared capacity for implicit computation.

There have been previous proposals in cognitive science that are related to implicit computation, as noted below (e.g., Dodwell, 1983; Gallistel, 1990; Hoffman, 1966; Pizlo, 2010, 2019; Shepard, 1984, 1994). But the intellectual lineage of these ideas can be traced to Helmholtz' (1867) concept of 'unconscious inference' and Poincaré's (1905) analysis of the 
perception of space, and ultimately back to Kant. For example, Poincaré wrote: "The object of geometry is the study of a particular 'group'; but the general concept of group pre-exists in our minds, at least potentially. It is imposed on us not as a form of our sensitiveness, but as a form of our understanding; only, from among all possible groups, we must choose the one that will be the standard, so to speak, to which we shall refer natural phenomena" $(1905, \mathrm{p}$. 82, emphasis in original; see also Cassirer, 1944, for a discussion of algebraic groups and theories of perception, and Cutting, 1986, p. 61-75 for a historical summary and critical perspective).

We argue that implicit computation, as defined here, provides an integrative perspective and a common basis, for the first time, for understanding core knowledge phenomena across species. Moreover, by framing the capacity for structured representations in general terms, our proposal suggests a research agenda to understand why organisms have this capacity and a novel perspective on computation as structure, which complements the traditional view in cognitive science of computation as an action or function performed by the mind or brain (Churchland \& Sejnowski, 2016; Milkowski, 2013). Next we consider how implicit computation applies to individual core knowledge systems.

\subsection{Objects}

The object intuitions that are part of core knowledge relate to both existence and motion in space, and include permanence (objects are unitary and bounded wholes that continue to exist if blocked entirely or partially by an occluder), cohesion (objects remain unitary and bounded as the move), and continuity (objects move on connected paths; Spelke \& Kinzler, 2007). 
Core knowledge also supports viewpoint invariance, a key component of object recognition (i.e., objects can be identified from novel viewpoints; Wood, 2013).

All these attributes are described naturally by algebraic groups and related concepts. If an object is defined as a closed set of points in Euclidean 3D space, then the possible translations and rotations of the object can be represented as a six-dimensional manifold (three dimensions for position, three dimensions for rotation), as shown by Carlton and Shepard (1990a, 1990b; see also Shepard, 1994). These translations and rotations comprise the group of rigid transformations in Euclidean 3D, which is the mathematical formalism necessary to describe the kinematics of moving bodies. If a scaling factor is added, the result is a similarity transformation group (Figure 7) with seven degrees of freedom. The angles between triples of points are invariant under the action of a similarity group, which means that the shape of 3D objects are preserved (Pizlo, 2010, 2019). The similarity group describes the viewpoint invariance that an observer perceives while moving through an environment with objects. Thus the key results predicted by the object core knowledge system are consistent with our hypothesis that organisms can form representations with algebraic structure.

The idea that representations with algebraic structure are necessary for perceptual constancy and object recognition as an organism moves within an environment was earlier proposed by Hoffman (1966). In his Lie transformation group model of perception and neuropsychology (LTG/NP), Hoffman showed how the mathematics of continuous symmetries described by Lie groups and algebras could account for a range of perceptual phenomena. His model assumes that visual cortex represents a manifold and associated Lie algebra. Differential 
operators (which form a basis in Cartesian, polar or hyperbolic coordinates) act to recognize kinds of transformations (e.g., optic flow) and compensate for the affine transformations of objects associated with motion (see Dodwell, 1983, for an accessible tutorial on LTG/NP). Hoffman's theory can be regarded as an attempt to define the invariants identified in Gibson's $(1950,1979)$ ecological theory of perception. Although LTG/NP has had relatively little influence in psychology, Dodwell remarked that "this model, or one along closely similar lines, has to be correct, given the evident fact of stable spatial vision and pattern recognition under the vagaries of the perceiver's locomotion" (1983, p. 11). Recent advances in machine vision and learning, which have made explicit use of group-theoretic symmetries and transformations (e.g., Anselmi et al., 2016; Higgins et al., 2018; Leibo, Liao, Anselmi, Freiwald, \& Poggio, 2017; Poggio \& Anselmi, 2016), confirm the practicality of this approach.

A

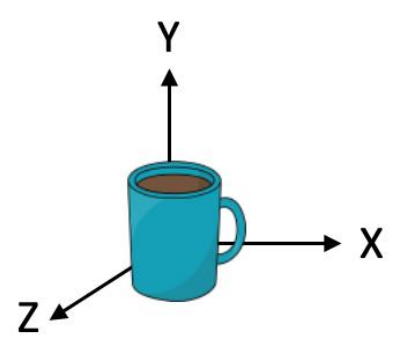

C
B

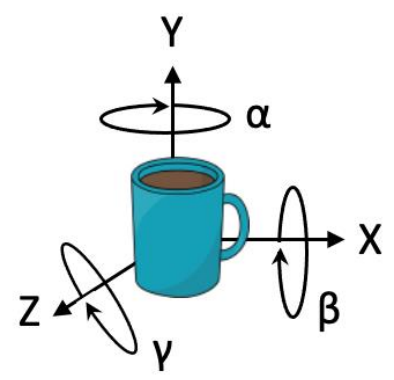

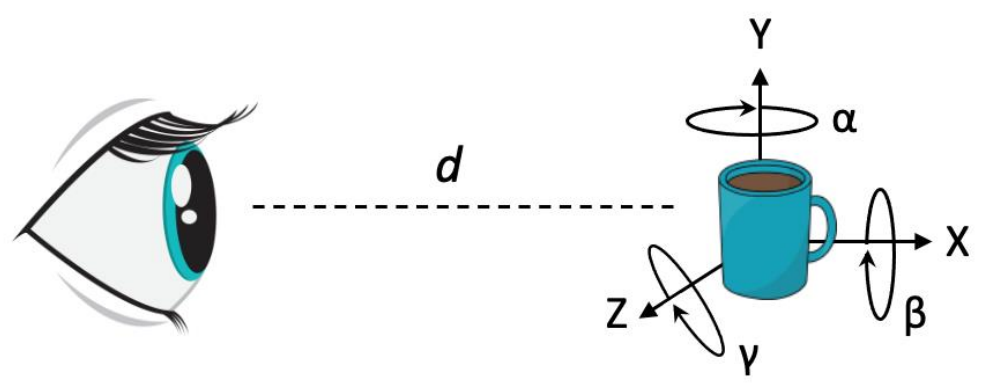


Figure 7. Illustration of the similarity transformation group that describes object recognition. An object is invariant under translation of its position $(A)$ and rotations around each axis $(B)$ in Euclidean $3 D$ space, which defines a six-dimensional manifold. The object's shape is preserved as the viewer's distance (d) varies (C).

Pizlo has also advanced some ideas that are similar to the present proposal. Pizlo (2001) emphasized that perception was an inverse problem, as the organism's task was to construct a veridical 3D representation of the world given the $2 \mathrm{D}$ input of retinal stimulation - the only way that this problem can be solved is if constraints or priors are imposed on the optic array.

Pizlo (2010) proposed a theory of 3D shape perception in which solved the inverse problem by applying a simplicity principle - that organisms were predisposed by evolution to infer the simplest reconstruction of a 3D scene based on the 2D retinal input. These ideas were developed further in Pizlo (2014), emphasizing the role of symmetry in 3D shape perception. Recently, he has proposed that symmetry plays an analogous role in physics and psychophysics, and that a 'least action' principle, fundamental in physics, connects mental representations with the outside world (Pizlo, 2019). Pizlo's proposals are similar to implicit computation as attempts to specify the priors imposed by the visual system that solve the problem of 3D shape perception.

\subsection{Space}

The spatial intuitions supported by core knowledge are associated with the shape of the environment, including distances, angles, and sense relations among boundaries and extended surfaces. The basic finding with the spatial reorientation task in a rectangular environment is that organisms treat as equivalent corners that have the same sense relation (e.g., relatively short on the left, relatively long on the right; Cheng, 1986). If the environment is regarded as 
a 3D shape that can be viewed from different allocentric perspectives, then the set of possible views are related by a similarity group transformation in which the target corner and its opposite are equivalent (see Figure 1D). Perception of a sense relation also requires that lengths (distances) are represented as magnitudes and the perceptual system can compute their ratio (left/right). This suggests that the perceptual system can represent (at a minimum) a group structure based on magnitudes.

\subsection{Number}

The core knowledge system for number is believed to comprise two subsystems, one that accurately identifies small numbers of objects ('subitizing'; typically no more than 3-4 discrete objects) and an 'approximate number system' (ANS) that represents larger numerosities and is capable of performing computations on them (Feigenson et al., 2004). Thus the core knowledge system is assumed to represent both discrete and continuous magnitudes. As reviewed above, studies have documented a 'perceptual arithmetic' in which infants can perform addition and subtraction on small numbers of discrete objects (Wynn, 1992), and this ability has also been found in nonhumans (including insects; Howard et al. 2019). The ANS also supports operations on continuous magnitudes, including addition and subtraction (Barth et al., 2006), multiplication (McCrink \& Spelke, 2010) and division (McCrink \& Spelke, 2016). These abilities are found in young children without formal mathematical instruction, indicating they are part of core knowledge.

These results suggest that the perceptual system can represent both continuous and discrete numerical magnitudes with algebraic structure. However some questions remain. Algebraic 
representations might seem intuitively reasonable for object recognition and perceptual constancy, but the ANS supports approximate representations of numerosity. How can an algebraic representation be imprecise? Several points can be noted. First, the degree of imprecision is systematically related to magnitude by Weber's law, and it is possible that the representation is structured so as to incorporate scalar variability (i.e., variability increases proportionally with the mean). One advantage of scalar variability is that it allows for a very wide range of physical values to be represented by effectively producing a logarithmic scale, and so is highly adaptive. Second, numerosity is fundamentally an abstraction; it is a property of collections of objects in the environment, not the objects or environment themselves. Representations of abstract or nonphysical properties may necessarily be less precise. Nevertheless, evidence that core knowledge supports operations on numerosities suggests a similar group-type structure for the representations. Other evidence in favor of this proposal is discussed below in $§ 5$. Finally, an important question is whether continuous and discrete magnitudes are represented separately or might be part of a single structure. There are algebraic objects such as Lie groups that are continuous but have discrete subgroups, and which might be the appropriate level of abstraction to represent numerosity.

\subsection{Time}

There have been comparatively few studies on timing with infants, and perhaps for that reason timing is not typically considered as a separate core knowledge system. In contrast, there is an extensive research literature on timing with nonhumans (Buhusi \& Meck, 2005; Gibbon, 1977; Killeen \& Fetterman, 1988; Kononowicz et al., 2018; Machado, 1997). Research shows that nonhuman animals are able to learn temporal intervals between events 
(e.g., between the onset of a stimulus and food delivery) and to respond adaptively as if time is represented as a continuous magnitude and operations can be performed on the representations. Some representative findings are described here.

When pigeons are exposed to delays between the onset of a signal (e.g., a lighted key) and food that change frequently, temporal characteristics of their responding (e.g., latency to peck the key) are linearly related to delay and show rapid adaptation to new delays (e.g., Kyonka \& Grace, 2007; Higa et al., 1991). This suggests that time is represented as a continuous magnitude. An example that suggests an operation performed on represented delays is temporal bisection (Church \& Deluty, 1977). If rats are trained on a task in which responses to one lever are reinforced with food after a short-duration signal (e.g., 2-s noise) while responses to another lever are reinforced after a long-duration signal (e.g., 8-s noise) and are later tested with intermediate durations, their responding shows a characteristic psychometric function with a bisection point at the geometric mean. This result suggests that remembered temporal intervals are scaled logarithmically and can be averaged by the organism. Gibbon, Baldock, Locurto, Gold, and Terrace (1977) exposed pigeons to pairings of a keylight with food, and varied the keylight and intertrial durations across groups. They found that the required number of pairings until pigeons started pecking the key was determined by the ratio of the keylight to intertrial duration, not their absolute values.

An analogue to temporal subtraction has also been studied with nonhumans. Gibbon and Church (1981) used a choice procedure in which rats and pigeons chose between a 60-s delay to food and a 30-s 'standard' delay that was made available while the 60-s delay was elapsing. Subjects chose the 30 -s delay if it was available after $15 \mathrm{~s}$ of the 60 -s delay had 
elapsed, but chose the 60-s alternative if the standard was available after $45 \mathrm{~s}$, suggesting they were able to compare the standard delay with the elapsing 60-s delay. Similar results were reported with mice by Cordes, King, and Gallistel (2007).

\subsection{Computationally-complex behavior}

Examples of adaptive behaviour reviewed in $§ 2.5$ above suggest that many species (including insects) are able to perform the equivalent of algebraic operations on environmental variables. Spatial navigation is a prime example (Collett \& Collett, 2000; Etienne \& Jeffery, 2004; Srinivasan, 2015). After foraging trips, honeybees are known to communicate the distance and direction of a food source to other bees by a 'waggle dance' (Von Frisch, 1967). Menzel et al. (2011) showed that bees that observed a dance ('recruits') were able to combine communicated and learned vectors to generate a novel path to a food source. In their study, recruits were first trained to fly to a food source (F2 in Figure 8), and afterwards observed a dance from other bees ('dancers') that had flown to a different food source (F2). When the recruits later flew to F1 and the food was missing, they travelled directly to F2 without going back to the nest. Commenting on this result, Gallistel (2017) wrote: "If there is a way to compute the range-and-bearing vector, $\mathbf{d}$, from the F1 and F2 location vectors without implementing addition, subtraction, and multiplication, then someone could make an important contribution to theoretical neuroscience by explaining to do that. Absent an alternative, this example and many like it are evidence that these arithmetic operations are implemented in the brain on stored vectors, that is, on number strings stored in an engram" (p. 4). 


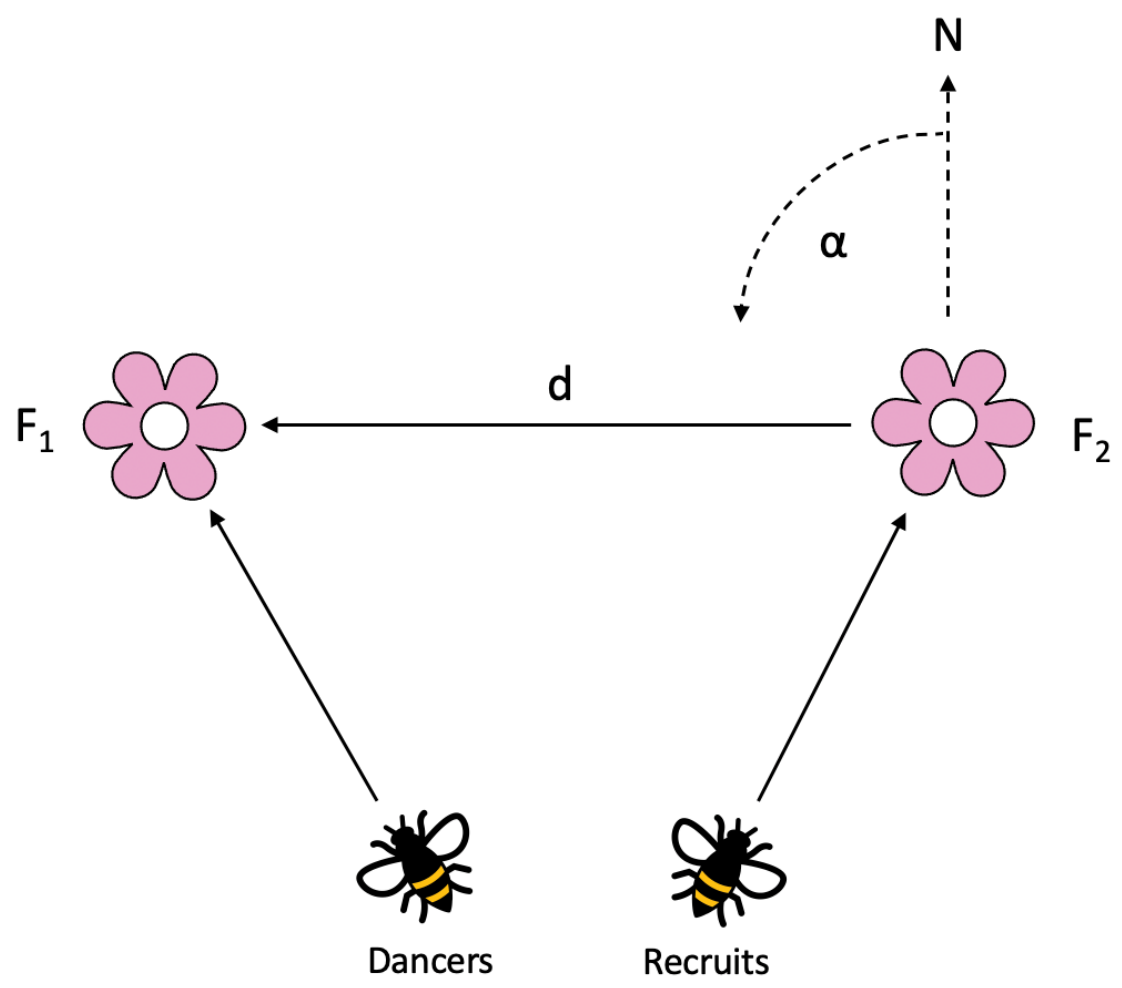

Figure 8. Illustration of Menzel et al.'s (2011) experiment in which bees that had learned to forage at a location (F2) and observed the dances of other bees that had learned to forage at a different location (F1), travelled directly to F1 without returning to the nest when had later flown to F2 and found that food was absent.

The most comprehensive account of computationally-complex behaviour has been proposed by Gallistel (1990). His 'computational-representational' theory of learning assumes that organisms represent environmental variables as real numbers and perform operations on them, and in subsequent work has elaborated accounts of many domains of animal learning, including conditioning (rate estimation theory - Gallistel \& Gibbon, 2000; timing - Balsam \& Gallistel, 2009; and choice behaviour - Gallistel et al., 2007; Kheifets \& Gallistel, 2012). We agree with the basic rationale of his theory that much adaptive behavior appears to require the equivalent of computation, but would question whether arithmetic operations on real numbers is the right level of abstraction to understand it - another possibility is to assume that magnitudes are represented as elements of an algebraic field (Grace et al., 2020). 
For present purposes, we will simply note that these examples and Gallistel's account support the general view that organisms have a capacity to form representations with algebraic structure, that is, a capacity for implicit computation.

\section{An Experimental Task ('Artificial Algebra') for Implicit Computation}

We have developed an experimental task to study implicit computation, in which participants (adults) learn to make an analogue response on the basis of an arithmetic combination of continuous magnitudes. We call the task an 'artificial algebra' because learning occurs by feedback and without explicit instruction, similar to artificial grammars used in psycholinguistics (Pothos, 2007). Results show evidence of 'footprints' of algebraic structure that was not specifically trained, suggesting that structure was part of the magnitude representations (Chen, Berg, Kemp, \& Grace, 2020; Grace, Morton, Ward, Wilson, \& Kemp, 2018). 
A

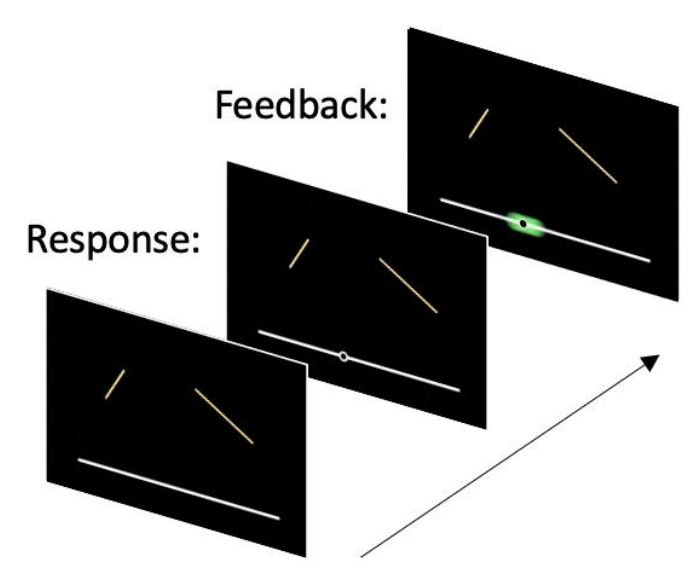

B

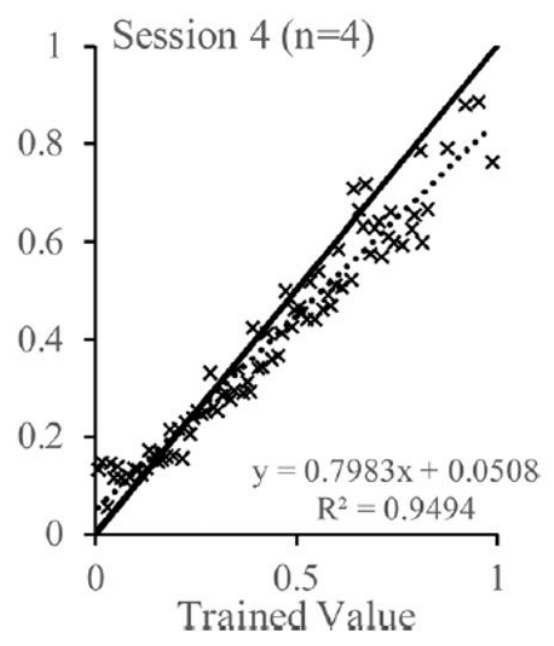

Figure 9. A. Sequence of trial events in the 'artificial algebra' task. B. Average results $(n=4)$ for participants given feedback based on differences of line lengths (Chen et al., 2020).

Figure 9A shows a diagram of a typical trial and representative results (9B). Participants view a pair of stimuli (e.g., two line segments) and respond by clicking on a horizontal bar. Feedback is provided based on response location, with 'correct' responses determined by an arithmetic combination of magnitudes, scaled linearly so that the minimum and maximum values are associated with the left and right ends of the bar, respectively. If the response is close to the correct location, a green feedback oval appears; if the response is not close, the oval is red and centered at the correct location. In our first experiments, participants were trained to respond based on either the difference or ratio of stimulus magnitudes. The rationale was to test a conjecture due to Torgerson (1961) that the perceptual system computes a single operation (either a difference or ratio) to compare magnitudes. Results showed that participants quickly learned to respond accurately $(r \sim .95$ within a single 35 -min session) with both differences and ratios. Analyses showed that responding was based on both operations, even though only one was trained. We concluded that the perceptual system 
automatically computed two operations when comparing magnitudes, suggesting that magnitudes are represented as elements of an algebraic field.

In further research with the artificial algebra task, we have shown that participants can learn to add magnitudes (line lengths and brightnesses) in accord with group axioms of associativity, commutativity, identity and inverse (Grace, Morton, Grice, Stuart, \& Kemp, 2020). These experiments used a transfer method in which participants were trained with a set of stimuli and later tested with novel stimuli without feedback. Responding was consistent with predictions in all cases, providing 'footprints' of the additive group axioms. We have also shown that participants suppress noise added to feedback based on differences or ratios,

supporting our prediction that these operations are automatically computed by the perceptual system (Morton, Wilson, Kemp, \& Grace, 2020). In summary, this research provides strong evidence that observers can implicitly learn to respond based on algebraic combinations of continuous, nonsymbolic magnitudes. Tests for footprints of structure suggest that the perceptual system represents magnitudes as elements of an algebraic field. The 'artificial algebra' task is a useful assay of implicit computation in adults, and could potentially be adapted for use with nonhumans.

\section{Why Implicit Computation? Nativism vs Empiricism 2.0}

The focal point of this paper is our inference that an ability to form representations of the world with algebraic structure is the best explanation for evidence across the animal kingdom of core knowledge systems and computationally-complex behavior. In the next two sections, we outline the broader implications of this view. We argue that implicit computation is a 
strategically important hypothesis, a linchpin for understanding cognition that provides a novel perspective on computation and machine intelligence and underscores the relevance of pure mathematics for the cognitive sciences.

If our hypothesis is correct, a key question arises: Why do organisms have a capacity for implicit computation? One possible answer is suggested by Shepard (1994), who argued that minds that evolved in a world characterized by Euclidean geometry and physical laws with algebraic structure would have effectively internalized the invariants of that world through natural selection. Shepard gave examples in which principles of group theory and geometry described the kinematics of apparent motion (Carlton \& Shepard, 1990a, 1990b) and perception of color constancy under varying illumination (Shepard, 1992). He emphasized the importance of aligning cognitive theory with the appropriate abstract space in which biologically-significant objects or attributes of the world could be described. Although Shepard's argument was based primarily on experimental data with adult humans, it can be applied equally well to core knowledge systems and provides an explanation for implicit computation, as discussed here: Organisms are able to form representations of the world with algebraic structure because their perceptual and cognitive systems evolved in a world characterized by that structure. Thus, mathematical concepts describe perception and cognition because mathematics describes the world. According to this view, the provenance of implicit computation results entirely from natural selection having internalized the geometric invariants of the world - which is a fundamentally empiricist account.

Is there an alternative explanation? Whereas natural selection undoubtedly accounts for variation across species, another possibility is that implicit computation also depends on 
factors that cannot be explained by environmental adaptation - that is, at least to some extent it is innate. This may sound like a radical idea but we argue it is plausible. For example, mathematical structure inherent in physical matter might have been embedded in the earliest unicellular organisms and provided a basis for implicit computation as more complex lifeforms evolved. The possibility that the universe is fundamentally mathematical in nature is taken seriously in the physical sciences (e.g., Tegmark, 2014) - if so, would not living organisms necessarily be able to form representations of their environment with mathematical structure?

These possibilities can be empirically investigated. If Shepard's (1994) theory is correct, then implicit computation should be limited to geometric spaces that are identical to the natural world, that is, locally Euclidean. By contrast, if algebraic structure is inherent in perceptual representations, implicit computation might not be constrained by the geometry of the world in which we evolved. Thus a critical test is to determine if implicit computation can be found in non-Euclidean spaces, for instance in navigation or learning the angles and distances associated with a novel geometry. Immersive virtual reality (VR) allows different geometric environments to be simulated (e.g., Hart, Hawksley, Matsumoto, \& Segerman, 2017a, 2017b), making it possible to test these hypotheses. Although there have been only limited studies, evidence suggests that participants are able to navigate and orient in nonEuclidean VR spaces without major disruption (Warren, 2019). This should be a promising avenue of future research.

More broadly, whether the provenance of implicit computation depends on innate factors or is due entirely to natural selection is analogous to a nature/nurture question. Just as the 
nature/nurture dialectic in developmental science ('Nativism vs Empiricism 1.0') has consistently revealed an interplay between phylogeny and ontogeny (Sameroff, 2010), we might anticipate that implicit computation also depends on both innate and evolved factors. The question might be described as 'Nativism vs. Empiricism 2.0' because it recapitulates the nature/nurture dialectic but over a broader evolutionary scale.

This is a question of fundamental importance. If algebraic structure is inherent in how organisms form representations of the world, then identifying the right level of abstraction to characterize it will be essential for progress in neuroscience. A similar proposal was made by Gallistel (2017), who argued that we needed to understand at the molecular level how information relating to an organism's experience was effectively coded as real numbers (e.g., in spatial navigation), citing our success in deciphering how information to construct an organism was encoded in DNA. The discovery of grid cells in the medial entorhinal cortex (Hafting, Fyhn, Molden, Moser, \& Moser, 2005), which fire in a regular hexagonal pattern as a rat traverses its environment, suggests that we may be close to understanding the neural basis of spatial orientation (Rowland, Roudi, Moser, \& Moser, 2016). The hexagonal pattern strongly hints at underlying symmetries in the representation of space, and computational models based on attractor networks have been proposed that can reproduce this result (Burak $\&$ Fiete, 2009). Despite the success of computational models in neuroscience, we argue in the next section that pure mathematics may also have an essential role.

\section{Penrose's Mysteries: Mathematics, Mind and the World}


The ideas proposed here can be considered most broadly in the nexus of relationships between the mind, mathematics and the world as diagrammed by Roger Penrose (2004). Near the beginning of his comprehensive presentation of modern physics for the educated layperson, The Road to Reality: A Complete Guide to the Laws of the Universe, Penrose describes three mysteries about the relations between the mind, the world, and mathematics. Penrose's mysteries, which encompass some of the most enduring dilemmas in philosophy as well as science, are displayed in Figure 10 (left panel).

A

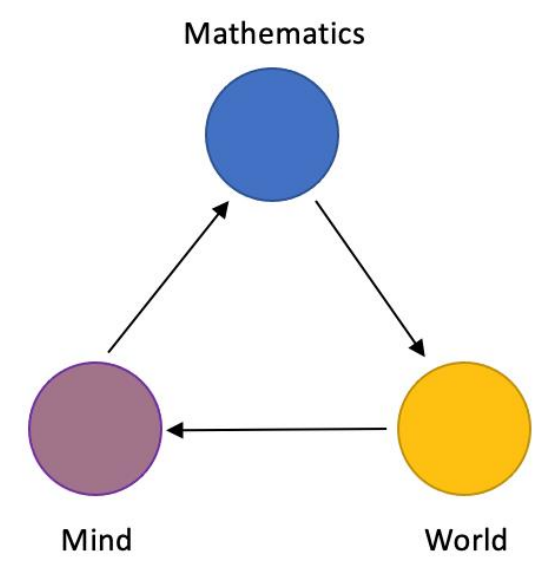

B

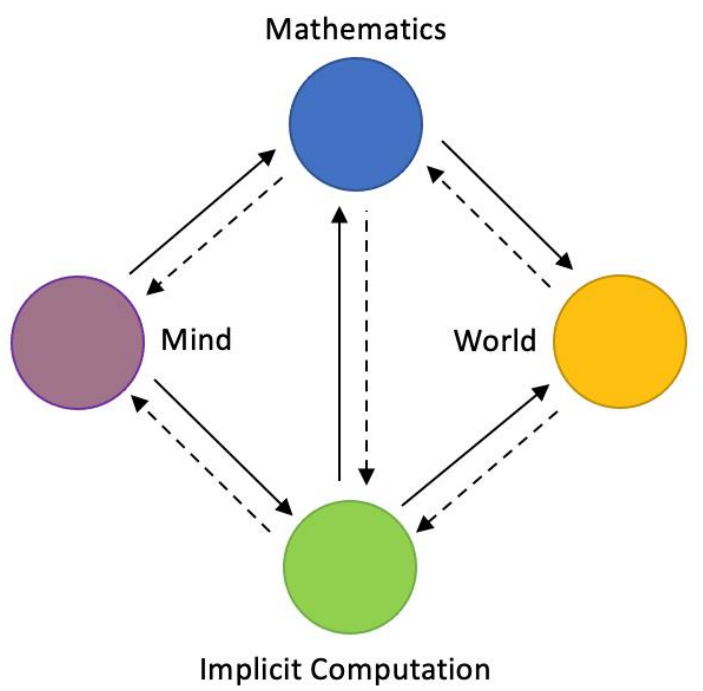

Figure 10. A. Diagram from Penrose (2004) describing three fundamental mysteries about the relationships between the mind, mathematics and the world. B. An expanded Penrose diagram that illustrates the present proposal: All relationships are bidirectional, and implicit computation mediates the relationship between the mind and world.

The first mystery (Mathematics $\rightarrow$ World) is why mathematical theories such as quantum mechanics and general relativity are so successful in making accurate predictions about the physical world. This 'unreasonable effectiveness' of mathematics in the physical sciences was famously noted by Wigner (1960), and later research has only confirmed this view (e.g., confirmation of predictions for physical constants such as the magnetic moment of the electron to accuracy of one part in billions; Odom, Hanneke, d'Urso, \& Gabrielse, 2006)). 
There are also many historical examples where mathematics developed purely out of curiosity turned out much later to be essential for physical theories (e.g., 'imaginary' numbers and complex analysis; non-Euclidean geometry; Lie algebras, and many others). As the physicist Steven Weinberg wrote, "It is as if Neil Armstrong in 1969 when he first set foot on the surface of the moon had found in the lunar dust the footsteps of Jules Verne" (Weinberg, 1994).

The second of Penrose's mysteries is how the mind can conceive of mathematics (Mind $\rightarrow$ Mathematics). As abstract creations of human minds, mathematical concepts such as a perfect circle or triangle seem to inhabit an idealized, Platonic realm that is open to our introspection (Shapiro, 1997). The mathematical realist view was famously stated by Gödel: "Despite their remoteness from sense experience, we do have something like a perception of the objects of set theory, as is seen from the fact that the axioms force themselves upon us as being true. I don't see any reason why we should have less confidence in this kind of perception, i.e., in mathematical intuition, than in sense perception" (Gödel, 1964). Others have argued strongly against mathematical realism (Benacerraf, 1973; Field, 2016), and the philosophy of mathematics remains widely debated (Shapiro, 1997, 2000).

Penrose's third mystery is how mental life can arise from matter (World $\rightarrow$ Mind). There has been considerable progress in neuroscience research on consciousness in the last two decades (Dehaene, Charles, King, \& Marti, 2014; Dehaene \& Naccache, 2001; Frewen et al., 2020; Frith, Perry, \& Lumer, 1999; Maia \& Cleeremans, 2005; Mashour, Roelfsema, Changeux, \& Dehaene, 2020; Tononi, 2004; Tononi, Boly, Massimini, \& Koch, 2016), leading to calls for 'consciousness science' to be recognized as a discipline (Michel et al., 2019). But significant 
challenges remain; the 'hard problem' of consciousness has not been solved (Chalmers, 2017; Overgaard, 2017; Tononi \& Koch, 2015), and there are vexing ethical questions, such as whether understanding the computational bases of consciousness will mean that robots can become self-aware (Dehaene, Lau, \& Kouider, 2017).

Fig 10 (left panel) might be called a Penrose diagram (not to be confused with his diagrams of spacetime; Penrose, 1963) and we propose an expanded version in the right panel. First, note that the relationships, and their attendant mysteries, are bidirectional. The left panel shows that mathematics mediates our knowledge of the world - which is certainly true, via its application in science (Mind $\rightarrow$ Mathematics $\rightarrow$ World). But humans and nonhumans have knowledge of the world that is not mediated by use of formal rules and abstract symbols, as amply demonstrated by the core knowledge systems reviewed here. Our argument is that implicit computation mediates this knowledge, and so provides a corresponding indirect path from Mind to World.

The expanded Penrose diagram in Figure 10 (right panel) clarifies these relationships. The indirect path Mind $\rightarrow$ Mathematics $\rightarrow$ World denotes the development of symbolic mathematics (or 'explicit computation') and its application via science to understand the world. The reverse of this path, World $\rightarrow$ Mathematics $\rightarrow$ Mind, is coming to fruition with the development of artificial intelligence (AI) - physical machines able to perform computation (i.e., digital computers) and their application to simulate and model cognition. Mind $\rightarrow$ Implicit Computation $\rightarrow$ World describes our current proposal that core knowledge systems are based on a capacity to form representations of the world with algebraic structure. The reverse path, World $\rightarrow$ Implicit Computation $\rightarrow$ Mind, suggests that to understand how 
consciousness arises from matter (World $\rightarrow$ Mind), we need to understand the mediating role of implicit computation (cf. Gallistel's 2017, 'coding hypothesis').

It is notable that a major reason for the remarkable success of AI in the last decade (e.g., image classification, speech recognition) is convolutional neural networks (CNNs; Rawat \& Wang, 2017). CNNs - also known as 'space invariant artificial neural networks' - include a kernel operator that effectively hardwires the translation symmetry inherent in visual perception into the network (LeCun \& Bengio, 1995; LeCun et al., 1989). From our perspective, these networks simulate implicit computation. Understanding how organisms form representations of the world with algebraic structure should lead to further advances in AI.

Our expanded Penrose diagram also suggests that implicit computation and mathematics may be related, in ways that provide insight into the philosophy of mathematics and its potential application in neuroscience. Mathematical concepts are necessary for understanding implicit computation (Mathematics $\rightarrow$ Implicit Computation). If our hypothesis is correct, it is remarkable to consider that it took humans literally thousands of years to describe in symbols what honeybees and other insects were doing all along. Pure mathematics provides a gateway and source of ideas for understanding implicit computation, so neuroscience should not just emphasize computational modelling, but identify the mathematical concepts (and level of abstraction) that characterize the structures that support implicit computation. In turn, implicit computation may provide the source for the intuitions that lead to symbolic mathematics. Elsewhere we have shown that assumptions of monotonicity, convexity, continuity and isomorphism are sufficient to derive arithmetic and algebraic structure (Grice, 
Morton, Kemp, \& Grace, 2020). It may be that these assumptions correspond to the core psychological intuitions of a living, moving organism aware of its environment.

Finally, we return to the mystery that Penrose (2004) was most fascinated by - the 'unreasonable effectiveness' of mathematics in the physical sciences (Wigner, 1960).

This has only grown more mysterious since 1960 (McDonnell, 2017), and trying to understand it has become a cottage industry in the philosophy of science (e.g., GrattanGuinness, 2008; Hamming, 1980; Islami, 2017; Islami \& Wiltsche, 2020; Omnès, 2011; Steiner, 2009). Although we cannot give a definitive answer, our expanded Penrose diagram suggests a correspondence: Mathematics may describe the physical world for the same reason that organisms can form representations of the world with algebraic structure. If our proposal is correct, understanding implicit computation may provide clues about why mathematics describes the physical world.

\section{Conclusion}

Our understanding of the origins of knowledge, both in philosophy and cognitive science, has pivoted on a dialectic between nativism (or rationalism) and empiricism, but evidence of core knowledge systems argues strongly against the mind as a tabula rasa. We propose a novel account of computation as the structure inherent in representations that organisms form of their environments. If these representations have algebraic structure, then computation would be inherent or implicit in them. Computation is thus regarded as structure rather than as an action or function - as has been the traditional assumption in cognitive science with attempts 
to model or simulate cognition via computational methods (e.g., neural networks, hierarchical Bayesian models). Computation as structure is fundamentally a Kantian view, and asking why organisms have this capacity leads to another iteration of the nativism/empiricism dialectic: Either the geometric invariants of the world have been internalized by evolution (Shepard, 1994), or mathematical structure is intrinsic to the mind. Addressing these questions will no doubt prove challenging, but our reasoning suggests that implicit computation, as described here, is a linchpin hypothesis that can potentially unlock some of the deepest mysteries in mathematics, philosophy and science. 


\section{Funding Statement:}

This research is supported by the Marsden Fund Council from Government funding, administered by the Royal Society of New Zealand (UOC-1603).

\section{Conflicts of Interest.}

None. 


\section{References}

Addyman, C., Rocha, S., \& Mareschal, D. (2014). Mapping the origins of time: scalar errors in infant time estimation. Developmental Psychology, 50(8), 2030-2035.

Amso, D., \& Johnson, S. P. (2006). Learning by selection: Visual search and object perception in young infants. Developmental Psychology, 42(6), 1236-1245.

Anselmi, F., Leibo, J. Z., Rosasco, L., Mutch, J., Tacchetti, A., \& Poggio, T. (2016). Unsupervised learning of invariant representations. Theoretical Computer Science, $633,112-121$.

Aslin, R. N., \& Newport, E. L. (2012). Statistical learning: From acquiring specific items to forming general rules. Current Directions in Psychological Science, 21(3), 170-176.

Bailey, T., \& Durrant-Whyte, H. (2006). Simultaneous localization and mapping (SLAM):

Part II. IEEE Robotics \& Automation Magazine, 13(3), 108-117.

Baillargeon, R. (1986). Representing the existence and the location of hidden objects: Object permanence in 6-and 8-month-old infants. Cognition, 23(1), 21-41.

Baillargeon, R. (2008). Innate ideas revisited: For a principle of persistence in infants' physical reasoning. Perspectives on Psychological Science, 3(1), 2-13.

Baillargeon, R., \& DeVos, J. (1991). Object permanence in young infants: Further evidence. Child Development, 62(6), 1227-1246.

Baillargeon, R., Scott, R. M., \& Bian, L. (2016). Psychological reasoning in infancy. Annual Review of Psychology, 67, 159-186.

Baillargeon, R., Scott, R. M., He, Z., Sloane, S., Setoh, P., Jin, K.-s., . . Bian, L. (2015).

Psychological and Sociomoral Reasoning in Infancy. In M. Mikulincer, P. R. Shaver, E. Borgida \& J. A. Bargh (Eds.), APA Handbooks in Psychology. APA Handbook of 
Personality and Social Psychology, Vol. 1. Attitudes and Social Cognition (pp. 79150). American Psychological Association.

Baillargeon, R., Spelke, E. S., \& Wasserman, S. (1985). Object permanence in five-monthold infants. Cognition, 20(3), 191-208.

Balsam, P. D., \& Gallistel, C. R. (2009). Temporal maps and informativeness in associative learning. TRENDS in Neurosciences, 32(2), 73-78.

Barrett, H. C., \& Kurzban, R. (2006). Modularity in cognition: framing the debate. Psychological Review, 113(3), 628-647.

Barth, H., La Mont, K., Lipton, J., Dehaene, S., Kanwisher, N., \& Spelke, E. (2006). Nonsymbolic arithmetic in adults and young children. Cognition, 98(3), 199-222.

Baum, W. M., \& Rachlin, H. C. (1969). Choice as time allocation. Journal of the Experimental Analysis of Behavior, 12(6), 861-874.

Benacerraf, P. (1973). Mathematical truth. The Journal of Philosophy, 70(19), 661-679.

Bogartz, R. S., Shinskey, J. L., \& Schilling, T. H. (2000). Object permanence in five-and-ahalf-month-old infants? Infancy, 1(4), 403-428.

Boole, G. (1854). An Investigation of the Laws of Thought: On Which are Founded the Mathematical Theories of Logic and Probabilities. Walton and Maberly.

Brannon, E. M., Roussel, L. W., Meck, W. H., \& Woldorff, M. (2004). Timing in the baby brain. Cognitive Brain Research, 21(2), 227-233.

Bremner, J. G., Johnson, S. P., Slater, A., Mason, U., Foster, K., Cheshire, A., \& Spring, J. (2005). Conditions for young infants' perception of object trajectories. Child Development, 76(5), 1029-1043.

Buhusi, C. V., \& Meck, W. H. (2005). What makes us tick? Functional and neural mechanisms of interval timing. Nature Reviews Neuroscience, 6(10), 755-765. 
Burak, Y., \& Fiete, I. R. (2009). Accurate path integration in continuous attractor network models of grid cells. PLoS Compututational Biology, 5(2), e1000291.

Burton, D. M. (1988). Abstract algebra. Dubuque, Iowa: William C Brown.

Carlton, E. H., \& Shepard, R. N. (1990a). Psychologically simple motions as geodesic paths I. Asymmetric objects. Journal of Mathematical Psychology, 34(2), 127-188.

Carlton, E. H., \& Shepard, R. N. (1990b). Psychologically simple motions as geodesic paths II. Symmetric objects. Journal of Mathematical Psychology, 34(2), 189-228.

Cashon, C. H., \& Cohen, L. B. (2000). Eight-month-old infants' perception of possible and impossible events. Infancy, 1(4), 429-446.

Cassirer, E. (1944). The concept of group and the theory of perception. Philosophy and Phenomenological Research, 5(1), 1-36.

Chalmers, D. (2017). The hard problem of consciousness. The Blackwell Companion to Consciousness, 2, 32-42.

Chen, Q., \& Li, J. (2014). Association between individual differences in non-symbolic number acuity and math performance: A meta-analysis. Acta Psychologica, 148, 163 172.

Chen, T. Y., Berg, M. E., Kemp, S., \& Grace, R. C. (2020). Differences and Ratios in a Nonsymbolic 'Artificial Algebra': Effects of Extended Training. Behavioural Processes, 180. 104242. 10.1016/j.beproc.2020.104242

Cheng, K. (1986). A purely geometric module in the rat's spatial representation. Cognition, 23(2), 149-178.

Cheng, K., Narendra, A., Sommer, S., \& Wehner, R. (2009). Traveling in clutter: navigation in the Central Australian desert ant Melophorus bagoti. Behavioural Processes, 80(3), 261-268. 
Cheng, K., \& Newcombe, N. S. (2005). Is there a geometric module for spatial orientation? Squaring theory and evidence. Psychonomic Bulletin \& Review, 12(1), 1-23.

Cheng, K., Shettleworth, S. J., Huttenlocher, J., \& Rieser, J. J. (2007). Bayesian integration of spatial information. Psychological Bulletin, 133(4), 625-637.

Chiandetti, C., Spelke, E. S., \& Vallortigara, G. (2015). Inexperienced newborn chicks use geometry to spontaneously reorient to an artificial social partner. Developmental Science, 18(6), 972-978.

Chiandetti, C., \& Vallortigara, G. (2008). Is there an innate geometric module? Effects of experience with angular geometric cues on spatial re-orientation based on the shape of the environment. Animal Cognition, 11(1), 139-146.

Chiandetti, C., \& Vallortigara, G. (2010). Experience and geometry: controlled-rearing studies with chicks. Animal Cognition, 13(3), 463-470.

Chiandetti, C., \& Vallortigara, G. (2011). Intuitive physical reasoning about occluded objects by inexperienced chicks. Proceedings of the Royal Society B: Biological Sciences, 278(1718), 2621-2627.

Christodoulou, J., Lac, A., \& Moore, D. S. (2017). Babies and math: A meta-analysis of infants' simple arithmetic competence. Developmental Psychology, 53(8), 1405-1417.

Church, R. M., \& Deluty, M. Z. (1977). Bisection of temporal intervals. Journal of Experimental Psychology: Animal Behavior Processes, 3(3), 216-228.

Churchland, P. S., \& Sejnowski, T. J. (2016). The Computational Brain. Cambridge, MA: MIT press.

Cohen, L. B., \& Marks, K. S. (2002). How infants process addition and subtraction events. Developmental Science, 5(2), 186-201.

Collett, M., \& Collett, T. S. (2000). How do insects use path integration for their navigation? Biological Cybernetics, 83(3), 245-259. 
Collett, T. S. (2019). Path integration: how details of the honeybee waggle dance and the foraging strategies of desert ants might help in understanding its mechanisms. Journal of Experimental Biology, 222(11), jeb205187.

Colombo, J., \& Richman, W. A. (2002). Infant timekeeping: Attention and temporal estimation in 4-month-olds. Psychological Science, 13(5), 475-479.

Cordes, S., King, A. P., \& Gallistel, C. (2007). Time left in the mouse. Behavioural Processes, 74(2), 142-151.

Cording, J. R., McLean, A. P., \& Grace, R. C. (2011). Testing the linearity and independence assumptions of the generalized matching law for reinforcer magnitude: A residual meta-analysis. Behavioural Processes, 87(1), 64-70.

Cutting, J. E. (1986). Perception with an Eye for Motion. Cambridge, MA: MIT Press. de Hevia, M. D., Izard, V., Coubart, A., Spelke, E. S., \& Streri, A. (2014). Representations of space, time, and number in neonates. Proceedings of the National Academy of Sciences, 111(13), 4809-4813.

Dehaene, S. (2011). The Number Sense: How the Mind Creates Mathematics. Oxford University Press.

Dehaene, S., Charles, L., King, J.-R., \& Marti, S. (2014). Toward a computational theory of conscious processing. Current Opinion in Neurobiology, 25, 76-84.

Dehaene, S., Lau, H., \& Kouider, S. (2017). What is consciousness, and could machines have it? Science, 358(6362), 486-492.

Dehaene, S., \& Naccache, L. (2001). Towards a cognitive neuroscience of consciousness: basic evidence and a workspace framework. Cognition, 79(1-2), 1-37.

Deppe, A. M., Wright, P. C., \& Szelistowski, W. A. (2009). Object permanence in lemurs. Animal Cognition, 12(2), 381-388. 
Derbyshire, J. (2006). Unknown quantity: A Real and Imaginary History of Algebra: National Academies Press.

DeWind, N. K., Park, J., Woldorff, M. G., \& Brannon, E. M. (2019). Numerical encoding in early visual cortex. Cortex, 114, 76-89.

Dodwell, P. C. (1983). The Lie transformation group model of visual perception. Perception \& Psychophysics, 34(1), 1-16.

Duncan, G. J., Dowsett, C. J., Claessens, A., Magnuson, K., Huston, A. C., Klebanov, P., .. . Brooks-Gunn, J. (2007). School readiness and later achievement. Developmental Psychology, 43(6), 1428-1446.

Durand, K., \& Lécuyer, R. (2002). Object permanence observed in 4-month-old infants with a 2D display. Infant Behavior and Development, 25(3), 269-278.

Durrant-Whyte, H., \& Bailey, T. (2006). Simultaneous localization and mapping: part I. IEEE Robotics \& Automation Magazine, 13(2), 99-110.

Ekstrom, A. D., \& Isham, E. A. (2017). Human spatial navigation: Representations across dimensions and scales. Current Opinion in Behavioral Sciences, 17, 84-89.

Ernst, M. O., \& Banks, M. S. (2002). Humans integrate visual and haptic information in a statistically optimal fashion. Nature, 415(6870), 429-433.

Etienne, A. S., \& Jeffery, K. J. (2004). Path integration in mammals. Hippocampus, 14(2), 180-192.

Evans, J. S. B. (2003). In two minds: dual-process accounts of reasoning. Trends in Cognitive Sciences, 7(10), 454-459.

Fazio, L. K., Bailey, D. H., Thompson, C. A., \& Siegler, R. S. (2014). Relations of different types of numerical magnitude representations to each other and to mathematics achievement. Journal of Experimental Child Psychology, 123, 53-72. 
Feigenson, L., Carey, S., \& Hauser, M. (2002). The representations underlying infants' choice of more: Object files versus analog magnitudes. Psychological Science, 13(2), 150156.

Feigenson, L., Dehaene, S., \& Spelke, E. (2004). Core systems of number. Trends in Cognitive Sciences, 8(7), 307-314.

Feigenson, L., Libertus, M. E., \& Halberda, J. (2013). Links between the intuitive sense of number and formal mathematics ability. Child Development Perspectives, 7(2), 74-79.

Field, H. (2016). Science Without Numbers. Oxford University Press.

Fiset, S., Beaulieu, C., \& Landry, F. (2003). Duration of dogs' (Canis familiaris) working memory in search for disappearing objects. Animal Cognition, 6(1), 1-10.

Fiset, S., \& Doré, F. Y. (2006). Duration of cats' (Felis catus) working memory for disappearing objects. Animal Cognition, 9(1), 62-70.

Fodor, J. A. (1975). The Language of Thought. Cambridge, MA: Harvard University Press.

Fodor, J. A. (1980). Methodological solipsism considered as a research strategy in cognitive psychology. Behavioral and Brain Sciences, 3(1), 63-73.

Fodor, J. A. (1983). The Modularity of Mind. Cambridge, MA: MIT Press.

Fodor, J. A., \& Pylyshyn, Z. W. (1988). Connectionism and cognitive architecture: A critical analysis. Cognition, 28(1-2), 3-71.

Frenkel, E. (2013). Love and Math: The Heart of Hidden Reality. Basic Books.

Frewen, P., Schroeter, M. L., Riva, G., Cipresso, P., Fairfield, B., Padulo, C., . . KusiMensah, K. (2020). Neuroimaging the consciousness of self: Review, and conceptualmethodological framework. Neuroscience \& Biobehavioral Reviews, 112, 164-212.

Friston, K. (2010). The free-energy principle: a unified brain theory? Nature Reviews Neuroscience, 11(2), 127-138. 
Frith, C., Perry, R., \& Lumer, E. (1999). The neural correlates of conscious experience: An experimental framework. Trends in Cognitive Sciences, 3(3), 105-114.

Funk, M. S. (1996). Development of object permanence in the New Zealand parakeet (Cyanoramphus auriceps). Animal Learning \& Behavior, 24(4), 375-383.

Gallistel, C. (2017). The coding question. Trends in Cognitive Sciences, 21(7), 498-508.

Gallistel, C., King, A. P., Gottlieb, D., Balci, F., Papachristos, E. B., Szalecki, M., \& Carbone, K. S. (2007). Is matching innate? Journal of the Experimental Analysis of Behavior, 87(2), 161-199.

Gallistel, C. R. (1990). The Organization of Learning. Cambridge, MA: MIT Press.

Gallistel, C. R. (2018). Finding numbers in the brain. Philosophical Transactions of the Royal Society B: Biological Sciences, 373(1740), 20170119.

Gallistel, C. R., \& Gibbon, J. (2000). Time, rate, and conditioning. Psychological Review, 107(2), 289-344.

Geary, D. C., Hoard, M. K., Nugent, L., \& Bailey, D. H. (2012). Mathematical cognition deficits in children with learning disabilities and persistent low achievement: a fiveyear prospective study. Journal of Educational Psychology, 104(1), 206-223.

Gebuis, T., \& Reynvoet, B. (2012). The interplay between nonsymbolic number and its continuous visual properties. Journal of Experimental Psychology: General, 141(4), 642-648.

Gershman, S. J., Horvitz, E. J., \& Tenenbaum, J. B. (2015). Computational rationality: A converging paradigm for intelligence in brains, minds, and machines. Science, 349(6245), 273-278.

Gibbon, J. (1977). Scalar expectancy theory and Weber's law in animal timing. Psychological Review, 84(3), 279-325. 
Gibbon, J., Baldock, M., Locurto, C., Gold, L., \& Terrace, H. (1977). Trial and intertrial durations in autoshaping. Journal of Experimental Psychology: Animal Behavior Processes, 3(3), 264-284.

Gibbon, J., \& Church, R. M. (1981). Time left: linear versus logarithmic subjective time. Journal of Experimental Psychology: Animal Behavior Processes, 7(2), 87-108.

Gibson, J. J. (1950). The Perception of the Visual World. Houghton Mifflin.

Gibson, J. J. (1979). The Ecological Approach to Visual Perception. Houghton Mifflin.

Gödel, K. (1964). What is Cantor's Continuum Problem? In W. P. Benacerraf \& H. Putnam (Eds.). Philosophy of Mathematics: Selected Readings, 258-272.

Gouteux, S., Thinus-Blanc, C., \& Vauclair, J. (2001). Rhesus monkeys use geometric and nongeometric information during a reorientation task. Journal of Experimental Psychology: General, 130(3), 505-519.

Grace, R. C., Carvell, G. E., Morton, N. J., Grice, M., Wilson, A. J., \& Kemp, S. (2020). On the origins of computationally complex behavior. Journal of Experimental Psychology: Animal Learning and Cognition, 46(1), 1-15.

Grace, R. C., Morton, N. J., Grice, M., Stuart, K., \& Kemp, S. (2020). Additive groups in a non-symbolic 'artificial algebra'. PsyArXiv. https://doi.org/10.31234/osf.io/k935n

Grace, R. C., Morton, N. J., Ward, M. D., Wilson, A. J., \& Kemp, S. (2018). Ratios and differences in perceptual comparison: A reexamination of Torgerson's conjecture. Journal of Mathematical Psychology, 85, 62-75.

Grattan-Guinness, I. (2008). Solving Wigner's mystery: The reasonable (though perhaps limited) effectiveness of mathematics in the natural sciences. The Mathematical Intelligencer, 30(3), 7-17. 
Grice, M., Morton, N. J., Kemp, S., \& Grace, R. C. (2020). Monotonicity, continuity, convexity, and isomorphism: The psychological scaffolding of arithmetic. PsyArXiv. https://doi.org/10.31234/osf.io/myq4n

Griffiths, T. L., Chater, N., Kemp, C., Perfors, A., \& Tenenbaum, J. B. (2010). Probabilistic models of cognition: Exploring representations and inductive biases. Trends in Cognitive Sciences, 14(8), 357-364.

Grondin, S. (2001). From physical time to the first and second moments of psychological time. Psychological Bulletin, 127(1), 22-44.

Grondin, S. (2010). Timing and time perception: a review of recent behavioral and neuroscience findings and theoretical directions. Attention, Perception, \& Psychophysics, 72(3), 561-582.

Hafting, T., Fyhn, M., Molden, S., Moser, M.-B., \& Moser, E. I. (2005). Microstructure of a spatial map in the entorhinal cortex. Nature, 436(7052), 801-806.

Haig, B. D. (2018). An abductive theory of scientific method. In Method Matters in Psychology (pp. 35-64). Springer.

Halberda, J., Mazzocco, M. M., \& Feigenson, L. (2008). Individual differences in non-verbal number acuity correlate with maths achievement. Nature, 455(7213), 665-668.

Hamming, R. W. (1980). The unreasonable effectiveness of mathematics. The American Mathematical Monthly, 87(2), 81-90.

Hart, V., Hawksley, A., Matsumoto, E. A., \& Segerman, H. (2017a). Non-euclidean virtual reality I: explorations of $H^{3}$. Paper presented at the Bridges 2017 Conference Proceedings.

Hart, V., Hawksley, A., Matsumoto, E. A., \& Segerman, H. (2017b). Non-euclidean virtual reality II: explorations of $H^{2}$ x E. arXiv:1702.04862. 
Harvey, B. M., Dumoulin, S. O., Fracasso, A., \& Paul, J. M. (2020). A network of topographic maps in human association cortex hierarchically transforms visual timing-selective responses. Current Biology, 30(8), 1424-1434. e1426.

Hassabis, D., Kumaran, D., Summerfield, C., \& Botvinick, M. (2017). Neuroscience-inspired artificial intelligence. Neuron, 95(2), 245-258.

Hauser, M. D., MacNeilage, P., \& Ware, M. (1996). Numerical representations in primates. Proceedings of the National Academy of Sciences, 93(4), 1514-1517.

Hawkins, T. (2012). Emergence of the Theory of Lie Groups: An Essay in the History of Mathematics 1869-1926. Springer Science \& Business Media.

Hermer-Vazquez, L., Spelke, E. S., \& Katsnelson, A. S. (1999). Sources of flexibility in human cognition: Dual-task studies of space and language. Cognitive Psychology, 39(1), 3-36.

Hermer, L., \& Spelke, E. (1996). Modularity and development: The case of spatial reorientation. Cognition, 61(3), 195-232.

Hermer, L., \& Spelke, E. S. (1994). A geometric process for spatial reorientation in young children. Nature, 370(6484), 57-59.

Herrnstein, R. J. (1961). Relative and absolute strength of response as a function of frequency of reinforcement. Journal of the Experimental Analysis of Behavior, 4(3), 267-272.

Heyes, C. M. (1998). Theory of mind in nonhuman primates. Behavioral and Brain Sciences, 21(1), 101-114.

Higa, J. J. (1997). Rapid timing of a single transition in interfood interval duration by rats. Animal Learning \& Behavior, 25(2), 177-184.

Higa, J. J., Wynne, C., \& Staddon, J. (1991). Dynamics of time discrimination. Journal of Experimental Psychology: Animal Behavior Processes, 17(3), 281-291. 
Higgins, I., Amos, D., Pfau, D., Racaniere, S., Matthey, L., Rezende, D., \& Lerchner, A. (2018). Towards a definition of disentangled representations. arXiv:1812.02230.

Hodgkin, L. (2005). A History of Mathematics: From Mesopotamia to Modernity. Oxford University Press.

Hoffman, W. C. (1966). The Lie algebra of visual perception. Journal of Mathematical Psychology, 3(1), 65-98.

Houston-Price, C., \& Nakai, S. (2004). Distinguishing novelty and familiarity effects in infant preference procedures. Infant and Child Development: An International Journal of Research and Practice, 13(4), 341-348.

Howard, S. R., Avarguès-Weber, A., Garcia, J. E., Greentree, A. D., \& Dyer, A. G. (2019). Numerical cognition in honeybees enables addition and subtraction. Science Advances, 5(2), eaav0961.

Islami, A. (2017). A match not made in heaven: on the applicability of mathematics in physics. Synthese, 194(12), 4839-4861.

Islami, A., \& Wiltsche, H. A. (2020). A match made on earth: On the applicability of mathematics in physics. In Phenomenological Approaches to Physics (pp. 157-177): Springer.

Izard, V., \& Spelke, E. S. (2009). Development of sensitivity to geometry in visual forms. Human Evolution, 23(3), 213-248.

Johnson, S. P., Slemmer, J. A., \& Amso, D. (2004). Where infants look determines how they see: Eye movements and object perception performance in 3-month-olds. Infancy, 6(2), 185-201.

Karmiloff-Smith, B. A. (1994). Beyond modularity: A developmental perspective on cognitive science. European Journal of Disorders of Communication, 29(1), 95-105. 
Kellman, P. J., \& Spelke, E. S. (1983). Perception of partly occluded objects in infancy. Cognitive Psychology, 15(4), 483-524.

Kheifets, A., \& Gallistel, C. (2012). Mice take calculated risks. Proceedings of the National Academy of Sciences, 109(22), 8776-8779.

Killeen, P. R., \& Fetterman, J. G. (1988). A behavioral theory of timing. Psychological Review, 95(2), 274-295.

Kononowicz, T. W., Van Rijn, H., \& Meck, W. H. (2018). Timing and time perception: A critical review of neural timing signatures before, during, and after the to-be-timed interval. In Stevens' Handbook of Experimental Psychology and Cognitive Neuroscience, 1, 1-38.

Krizhevsky, A., Sutskever, I., \& Hinton, G. E. (2012). Imagenet classification with deep convolutional neural networks. Advances in Neural Information Processing Systems, $25,1097-1105$.

Kruschke, J. K. (1992). ALCOVE: an exemplar-based connectionist model of category learning. Psychological Review, 99(1), 22-44.

Kyonka, E. G., \& Grace, R. C. (2007). Rapid acquisition of choice and timing in pigeons. Journal of Experimental Psychology: Animal Behavior Processes, 33(4), 392-408.

Kyonka, E. G., \& Grace, R. C. (2008). Rapid acquisition of preference in concurrent chains when alternatives differ on multiple dimensions of reinforcement. Journal of the Experimental Analysis of Behavior, 89(1), 49-69.

Lake, B. M., Ullman, T. D., Tenenbaum, J. B., \& Gershman, S. J. (2017). Building machines that learn and think like people. Behavioral and Brain Sciences, 40, e253.

Langille, J. J., \& Gallistel, C. R. (2020). Locating the engram: Should we look for plastic synapses or information-storing molecules? Neurobiology of Learning and Memory, $169,107164$. 
Leary, D. E. (1982). Immanuel Kant and the development of modern psychology. In W. R. Woodward \& M. C. Ash (Eds.), The Problematic Science: Psychology in NineteenthCentury Thought (pp. 17-42). New York: Praeger

LeCun, Y., \& Bengio, Y. (1995). Convolutional networks for images, speech, and time series. The Handbook of Brain Theory and Neural Networks, 3361 (10).

LeCun, Y., Boser, B., Denker, J. S., Henderson, D., Howard, R. E., Hubbard, W., \& Jackel, L. D. (1989). Backpropagation applied to handwritten zip code recognition. Neural Computation, 1(4), 541-551.

Lee, S. A. (2017). The boundary-based view of spatial cognition: a synthesis. Current Opinion in Behavioral Sciences, 16, 58-65.

Lee, S. A., Ferrari, A., Vallortigara, G., \& Sovrano, V. A. (2015). Boundary primacy in spatial mapping: Evidence from zebrafish (Danio rerio). Behavioural Processes, 119, 116-122.

Lee, S. A., Shusterman, A., \& Spelke, E. S. (2006). Reorientation and landmark-guided search by young children: Evidence for two systems. Psychological Science, 17(7), $577-582$.

Lee, S. A., \& Spelke, E. S. (2008). Children's use of geometry for reorientation. Developmental Science, 11(5), 743-749.

Lee, S. A., \& Spelke, E. S. (2010). Two systems of spatial representation underlying navigation. Experimental Brain Research, 206(2), 179-188.

Lee, S. A., \& Spelke, E. S. (2011). Young children reorient by computing layout geometry, not by matching images of the environment. Psychonomic Bulletin \& Review, 18(1), 192-198. 
Lee, S. A., Spelke, E. S., \& Vallortigara, G. (2012). Chicks, like children, spontaneously reorient by three-dimensional environmental geometry, not by image matching. Biology Letters, 8(4), 492-494.

Leibo, J. Z., Liao, Q., Anselmi, F., Freiwald, W. A., \& Poggio, T. (2017). View-tolerant face recognition and Hebbian learning imply mirror-symmetric neural tuning to head orientation. Current Biology, 27(1), 62-67.

Leibovich, T., Katzin, N., Harel, M., \& Henik, A. (2017). From "sense of number" to "sense of magnitude": The role of continuous magnitudes in numerical cognition. Behavioral and Brain Sciences, 40, e164.

Lipton, J. S., \& Spelke, E. S. (2003). Origins of number sense: Large-number discrimination in human infants. Psychological Science, 14(5), 396-401.

Lipton, P. (2003). Inference to the Best Explanation. Routledge.

Loomis, J. M., Klatzky, R. L., Golledge, R. G., Cicinelli, J. G., Pellegrino, J. W., \& Fry, P. A. (1993). Nonvisual navigation by blind and sighted: assessment of path integration ability. Journal of Experimental Psychology: General, 122(1), 73-91.

Lorenzi, E., Perrino, M., \& Vallortigara, G. (2021). Numerosities and Other Magnitudes in the Brains: A Comparative View. Frontiers in Psychology, 12, 1104.

Lurz, R., \& Krachun, C. (2019). Experience-projection methods in theory-of-mind research: Their limits and strengths. Current Directions in Psychological Science, 28(5), 456462.

Lurz, R., Krachun, C., Mahovetz, L., Wilson, M. J., \& Hopkins, W. (2018). Chimpanzees gesture to humans in mirrors: using reflection to dissociate seeing from line of gaze. Animal Behaviour, 135, 239-249.

Machado, A. (1997). Learning the temporal dynamics of behavior. Psychological Review, 104(2), 241-265. 
Mac Lane, S. (1986). Mathematics: Form and Function. New York: Springer-Verlag.

Maia, T. V., \& Cleeremans, A. (2005). Consciousness: Converging insights from connectionist modeling and neuroscience. Trends in Cognitive Sciences, 9(8), 397404.

Mandler, G., \& Shebo, B. J. (1982). Subitizing: an analysis of its component processes. Journal of Experimental Psychology: General, 111(1), 1-22.

Mashour, G. A., Roelfsema, P., Changeux, J.-P., \& Dehaene, S. (2020). Conscious processing and the global neuronal workspace hypothesis. Neuron, 105(5), 776-798.

McCrink, K., \& Spelke, E. S. (2010). Core multiplication in childhood. Cognition, 116(2), 204-216.

McCrink, K., \& Spelke, E. S. (2016). Non-symbolic division in childhood. Journal of Experimental Child Psychology, 142, 66-82.

McDonnell, J. (2017). Wigner's puzzle and the Pythagorean heuristic. Synthese, 194(8), 2931-2948.

Menzel, R., Kirbach, A., Haass, W.-D., Fischer, B., Fuchs, J., Koblofsky, M., . . Nguyen, H. (2011). A common frame of reference for learned and communicated vectors in honeybee navigation. Current Biology, 21(8), 645-650.

Michel, M., Beck, D., Block, N., Blumenfeld, H., Brown, R., Carmel, D., . . Cleeremans, A. (2019). Opportunities and challenges for a maturing science of consciousness. Nature Human Behaviour, 3(2), 104-107.

Milkowski, M. (2013). Explaining the Computational Mind. Cambridge, MA: MIT Press.

Miller, H. C., Rayburn-Reeves, R., \& Zentall, T. R. (2009). What do dogs know about hidden objects? Behavioural Processes, 81(3), 439-446. 
Miller, N. Y., \& Shettleworth, S. J. (2007). Learning about environmental geometry: an associative model. Journal of Experimental Psychology: Animal Behavior Processes, $33(3), 191-212$.

Miller, R. R., \& Grace, R. C. (2003). Conditioning and learning. In Experimental Psychology (A.F. Healy \& R.W. Proctor, Eds.), Vol 4, pp. 357-392, of Handbook of Psychology, Second Edition (I.B. Weiner, Ed.). New York: John Wiley \& Sons.

Mix, K. S., Huttenlocher, J., \& Levine, S. C. (2002). Multiple cues for quantification in infancy: Is number one of them? Psychological Bulletin, 128(2), 278-294.

Morton, N. J., Wilson, A., Kemp, S., \& Grace, R. C. (2020). Nonsymbolic Estimation of Ratios and Differences with Noisy Feedback. PsyArXiv, 10.31234/osf.io/jhnf

Müller, M., \& Wehner, R. (1988). Path integration in desert ants, Cataglyphis fortis. Proceedings of the National Academy of Sciences, 85(14), 5287-5290.

Mur-Artal, R., \& Tardós, J. D. (2017). Orb-slam2: An open-source slam system for monocular, stereo, and rgb-d cameras. IEEE Transactions on Robotics, 33(5), 12551262.

Murakami, H., Tomaru, T., \& Gunji, Y.-P. (2017). Interaction between path integration and visual orientation during the homing run of fiddler crabs. Royal Society Open Science, 4(9), 170954.

Natale, F., Antinucci, F., Spinozzi, G., \& Potí, P. (1986). Stage 6 object concept in nonhuman primate cognition: A comparison between gorilla (Gorilla gorilla gorilla) and Japanese macaque (Macaca fuscata). Journal of Comparative Psychology, 100(4), $335-339$.

Neugebauer, O. (1969). The Exact Sciences in Antiquity. Courier Corporation. 
Newcombe, N. S., \& Huttenlocher, J. (2007). Development of spatial cognition. In D. Kuhn \& R. S. Siegler (Eds.), Handbook of Child Psychology, Vol. 2: Cognition, Perception and Language (6 ${ }^{\text {th }}$ Edition; pp. 734-776). New York: Wiley.

Norris, D. (1994). Shortlist: A connectionist model of continuous speech recognition. Cognition, 52(3), 189-234.

Odom, B., Hanneke, D., d'Urso, B., \& Gabrielse, G. (2006). New measurement of the electron magnetic moment using a one-electron quantum cyclotron. Physical Review Letters, 97(3), 030801.

Omnès, R. (2011). Wigner's “unreasonable effectiveness of mathematics”, revisited. Foundations of Physics, 41(11), 1729.

Overgaard, M. (2017). The status and future of consciousness research. Frontiers in Psychology, 8, 1719.

Park, J., DeWind, N. K., Woldorff, M. G., \& Brannon, E. M. (2016). Rapid and direct encoding of numerosity in the visual stream. Cerebral Cortex, 26(2), 748-763.

Penn, D. C., Holyoak, K. J., \& Povinelli, D. J. (2008). Darwin's mistake: explaining the discontinuity between human and nonhuman minds. Behavioral and Brain Sciences, 31(2), 109-178.

Penn, D. C., \& Povinelli, D. J. (2007). On the lack of evidence that non-human animals possess anything remotely resembling a 'theory of mind'. Philosophical Transactions of the Royal Society B: Biological Sciences, 362(1480), 731-744.

Penrose, R. (1963). Asymptotic properties of fields and space-times. Physical Review Letters, $10(2), 66$.

Penrose, R. (2004). The Road to Reality: A Complete Guide to the Physical Universe: Jonathan Cape. 
Pepperberg, I. M., \& Funk, M. S. (1990). Object permanence in four species of psittacine birds: An African Grey parrot (Psittacus erithacus), an Illiger mini macaw (Ara maracana), a parakeet (Melopsittacus undulatus), and a cockatiel (Nymphicus hollandicus). Animal Learning \& Behavior, 18(1), 97-108.

Perfors, A., Tenenbaum, J. B., Griffiths, T. L., \& Xu, F. (2011). A tutorial introduction to Bayesian models of cognitive development. Cognition, 120(3), 302-321.

Piaget, J. (1954). The Construction of Reality in the Child. New York, NY: Routledge. Pinker, S. (2003). How the Mind Works. Penguin.

Pizlo, Z. (2001). Perception viewed as an inverse problem. Vision Research, 41(24), 31453161.

Pizlo, Z. (2010). 3D shape: Its Unique Place in Visual Perception. Cambridge, MA: MIT Press.

Pizlo, Z. (2014). Making a Machine that Sees Like Us. Oxford, UK: Oxford University Press.

Pizlo, Z. (2019). Unifying physics and psychophysics on the basis of symmetry, least-action simplicity principle, and conservation laws $\approx$ veridicality. The American Journal of Psychology, 132(1), 1-25.

Ploeger, A. \& Galis, F. (2011). Evo devo and cognitive science. WIREs Cognitive Science, 2, 429-440.

Poggio, T., \& Anselmi, F. (2016). Visual Cortex and Deep Networks: Learning Invariant Representations. Cambridge, MA: MIT Press.

Poincaré, H. (1905). Science and Hypothesis. Science Press.

Pothos, E. M. (2007). Theories of artificial grammar learning. Psychological Bulletin, 133(2), 227-244. 
Povinelli, D. J., \& Vonk, J. (2003). Chimpanzee minds: suspiciously human? Trends in Cognitive Sciences, 7(4), 157-160.

Putnam, H. (1967). The nature of mental states. Art, Mind, and Religion, 37-48.

Quinn, P. C., \& Johnson, M. H. (2000). Global-before-basic object categorization in connectionist networks and 2-month-old infants. Infancy, 1(1), 31-46.

Rawat, W., \& Wang, Z. (2017). Deep convolutional neural networks for image classification: A comprehensive review. Neural Computation, 29(9), 2352-2449.

Riley, J. R., Greggers, U., Smith, A. D., Reynolds, D. R., \& Menzel, R. (2005). The flight paths of honeybees recruited by the waggle dance. Nature, 435(7039), 205-207.

Rivera-Batiz, F. L. (1992). Quantitative literacy and the likelihood of employment among young adults in the United States. Journal of Human Resources, 313-328.

Rowland, D. C., Roudi, Y., Moser, M.-B., \& Moser, E. I. (2016). Ten years of grid cells. Annual Review of Neuroscience, 39, 19-40.

Rugani, R., Fontanari, L., Simoni, E., Regolin, L., \& Vallortigara, G. (2009). Arithmetic in newborn chicks. Proceedings of the Royal Society B: Biological Sciences, 276(1666), 2451-2460.

Rumelhart, D. E., McClelland, J. L., and the PDP Research Group (1986). Parallel Distributed Processing. Explorations in the Microstructure of Cognition: Vol 1. Foundations. Cambridge, MA: MIT Press.

Saffran, J. R., Aslin, R. N., \& Newport, E. L. (1996). Statistical learning by 8-month-old infants. Science, 274(5294), 1926-1928.

Sameroff, A. (2010). A unified theory of development: A dialectic integration of nature and nurture. Child Development, 81(1), 6-22.

Santolin, C., Rosa-Salva, O., Vallortigara, G., \& Regolin, L. (2016). Unsupervised statistical learning in newly hatched chicks. Current Biology, 26(23), R1218-R1220. 
Santolin, C., \& Saffran, J. R. (2018). Constraints on statistical learning across species. Trends in Cognitive Sciences, 22(1), 52-63.

Shapiro, S. (1997). Philosophy of Mathematics: Structure and Ontology. Oxford, UK:

Oxford University Press.

Shapiro, S. (2000). Thinking about Mathematics: The Philosophy of Mathematics. Oxford, UK: Oxford University Press.

Shen, K., Crossley, J. N., Lun, A. W.-C., \& Liu, H. (1999). The Nine Chapters on the Mathematical Art: Companion and Commentary. Oxford, UK: Oxford University Press.

Shepard, R. N. (1984). Ecological constraints on internal representation: Resonant kinematics of perceiving, imagining, thinking, and dreaming. Psychological Review, 91(4), 417447.

Shepard, R. N. (1992). The perceptual organization of colors: An adaptation to regularities of the terrestrial world? In J. H. Barkow, L. Cosmides, \& J. Tooby (Eds.), The Adapted Mind: Evolutionary Psychology and the Generation of Culture (p. 495-532). Oxford University Press.

Shepard, R. N. (1994). Perceptual-cognitive universals as reflections of the world. Psychonomic Bulletin \& Review, 1(1), 2-28.

Shettleworth, S. J. (2012). Modularity, comparative cognition and human uniqueness. Philosophical Transactions of the Royal Society B: Biological Sciences, 367(1603), 2794-2802.

Silver, D., Huang, A., Maddison, C. J., Guez, A., Sifre, L., Van Den Driessche, G., . . . Lanctot, M. (2016). Mastering the game of Go with deep neural networks and tree search. Nature, 529(7587), 484-489. 
Silver, D., Schrittwieser, J., Simonyan, K., Antonoglou, I., Huang, A., Guez, A., . . Bolton, A. (2017). Mastering the game of go without human knowledge. Nature, 550(7676), 354-359.

Simon, T. J., Hespos, S. J., \& Rochat, P. (1995). Do infants understand simple arithmetic? A replication of Wynn (1992). Cognitive Development, 10(2), 253-269.

Singer, R., \& Henderson, E. (2015). Object permanence in marine mammals using the violation of expectation procedure. Behavioural Processes, 112, 108-113.

Spelke, E., Lee, S. A., \& Izard, V. (2010). Beyond core knowledge: Natural geometry. Cognitive Science, 34(5), 863-884.

Spelke, E. S. (1990). Principles of object perception. Cognitive Science, 14(1), 29-56.

Spelke, E. S. (1998). Nativism, empiricism, and the origins of knowledge. Infant Behavior and Development, 21(2), 181-200.

Spelke, E. S. (2000). Core knowledge. American Psychologist, 55(11), 1233-1243.

Spelke, E. S., Bernier, E. P., \& Skerry, A. (2013). Core social cognition. In M. R. Banaji \& S. A. Gelman (Eds.), Navigating the Social World: What Infants, Children and Other Species can Teach Us (pp. 11-16). Oxford University Press.

Spelke, E. S., Breinlinger, K., Macomber, J., \& Jacobson, K. (1992). Origins of knowledge. Psychological Review, 99(4), 605-632.

Spelke, E. S., Katz, G., Purcell, S. E., Ehrlich, S. M., \& Breinlinger, K. (1994). Early knowledge of object motion: Continuity and inertia. Cognition, 51(2), 131-176.

Spelke, E. S., Kestenbaum, R., Simons, D. J., \& Wein, D. (1995). Spatiotemporal continuity, smoothness of motion and object identity in infancy. British Journal of Developmental Psychology, 13(2), 113-142.

Spelke, E. S., \& Kinzler, K. D. (2007). Core knowledge. Developmental Science, 10(1), 8996. 
Srinivasan, M. V. (2010). Honey bees as a model for vision, perception, and cognition. Annual Review of Entomology, 55, 267-284.

Srinivasan, M. V. (2015). Where paths meet and cross: navigation by path integration in the desert ant and the honeybee. Journal of Comparative Physiology A, 201(6), 533-546.

Starkey, P., \& Cooper, R. G. (1980). Perception of numbers by human infants. Science, 210(4473), 1033-1035.

Starr, A., Libertus, M. E., \& Brannon, E. M. (2013). Number sense in infancy predicts mathematical abilities in childhood. Proceedings of the National Academy of Sciences, 110(45), 18116-18120.

Steiner, M. (2009). The applicability of mathematics as a philosophical problem. Harvard University Press.

Stone, T., Webb, B., Adden, A., Weddig, N. B., Honkanen, A., Templin, R., . . Heinze, S. (2017). An anatomically constrained model for path integration in the bee brain. Current Biology, 27(20), 3069-3085. e3011.

Strawson, P. (1966). The Bounds of Sense: An essay on Kant's Critique of Pure Reason. Methven \& Co.

Stürzl, W., Cheung, A., Cheng, K., \& Zeil, J. (2008). The information content of panoramic images I: The rotational errors and the similarity of views in rectangular experimental arenas. Journal of Experimental Psychology: Animal Behavior Processes, 34(1), 1-14.

Tegmark, M. (2014). Our Mathematical Universe: My Quest for the Ultimate Nature of Reality. Vintage.

Tenenbaum, J. B., Kemp, C., Griffiths, T. L., \& Goodman, N. D. (2011). How to grow a mind: Statistics, structure, and abstraction. Science, 331(6022), 1279-1285.

Thagard, P. (1989). Explanatory coherence. Behavioral and Brain Sciences, 12(3), 435-502. 
Tolman, E. C. (1948). Cognitive maps in rats and men. Psychological Review, 55(4), 189208.

Tommasi, L., Chiandetti, C., Pecchia, T., Sovrano, V. A., \& Vallortigara, G. (2012). From natural geometry to spatial cognition. Neuroscience \& Biobehavioral Reviews, 36(2), 799-824.

Tononi, G. (2004). An information integration theory of consciousness. BMC neuroscience, $5(1), 1-22$.

Tononi, G., Boly, M., Massimini, M., \& Koch, C. (2016). Integrated information theory: from consciousness to its physical substrate. Nature Reviews Neuroscience, 17(7), $450-461$.

Tononi, G., \& Koch, C. (2015). Consciousness: here, there and everywhere? Philosophical Transactions of the Royal Society B: Biological Sciences, 370(1668), 20140167.

Torgerson, W. S. (1961). Distances and ratios in psychophysical scaling. Acta Psychologica, 19, 201-205.

Twyman, A. D., Newcombe, N. S., \& Gould, T. J. (2009). Of mice (Mus musculus) and toddlers (Homo sapiens): evidence for species-general spatial reorientation. Journal of Comparative Psychology, 123(3), 342-345.

Ullman, T. D., \& Tenenbaum, J. B. (2020). Bayesian models of conceptual development: Learning as building models of the world. Annual Review of Developmental Psychology, 2, 533-558.

VanMarle, K., \& Wynn, K. (2006). Six-month-old infants use analog magnitudes to represent duration. Developmental Science, 9(5), F41-F49.

Verguts, T., \& Fias, W. (2005). Interacting neighbors: A connectionist model of retrieval in single-digit multiplication. Memory \& Cognition, 33(1), 1-16. 
Von Frisch, K. (1967). The Dance Language and Orientation of Bees. Harvard University Press.

Von Helmholtz, H. (1867). Handbuch der physiologischen Optik. Voss.

Wagner, G. P., Pavlicev, M., \& Cheverud, J. M. (2007). The road to modularity. Nature Reviews Genetics, 8(12), 921-931.

Walsh, V. (2003). A theory of magnitude: common cortical metrics of time, space and quantity. Trends in Cognitive Sciences, 7(11), 483-488.

Walsh, V. (2015). A theory of magnitude: The parts that sum to number. In R. C. Kadosh \& A. Dowker (Eds.), Oxford Library of Psychology. The Oxford Handbook of Numerical Cognition (pp. 552-565). Oxford University Press.

Wang, R. F., \& Spelke, E. S. (2002). Human spatial representation: Insights from animals. Trends in Cognitive Sciences, 6(9), 376-382.

Warren, W. H. (2019). Non-euclidean navigation. Journal of Experimental Biology, 222 (Suppl 1), jeb187971.

Webb, B. (2019). The internal maps of insects. Journal of Experimental Biology, 222 (Suppl 1), jeb188094.

Weinberg, S. (1994). Dreams of a Final Theory: Vintage.

West-Eberhard, M. J. (2003). Developmental Plasticity and Evolution. Oxford University Press.

Wigner, E. (1960). The Unreasonable Effectiveness of Mathematics in the Natural Sciences. Communications in Pure and Applied Mathematics, Vol. 13, No. 1.

Wilson, A. J., \& Dehaene, S. (2007). Number sense and developmental dyscalculia. In D. Coch, G. Dawson \& K. W. Fischer (Eds.), Human Behavior, Learning, and the Developmental Brain: Atypical Development (pp. 212-238). The Guilford Press. 
Wood, J. N. (2013). Newborn chickens generate invariant object representations at the onset of visual object experience. Proceedings of the National Academy of Sciences, 110(34), 14000-14005.

Wood, S. M., \& Wood, J. N. (2021). One-shot object parsing in newborn chicks. Journal of Experimental Psychology: General. https://doi.org/10.1037/xge0001043

Wynn, K. (1992). Addition and subtraction by human infants. Nature, 358(6389), 749-750.

Wystrach, A., \& Beugnon, G. (2009). Ants learn geometry and features. Current Biology, 19(1), 61-66.

Wystrach, A., Mangan, M., \& Webb, B. (2015). Optimal cue integration in ants. Proceedings of the Royal Society B: Biological Sciences, 282(1816), 20151484.

Xu, F. (2003). Numerosity discrimination in infants: Evidence for two systems of representations. Cognition, 89(1), B15-B25.

Xu, F., \& Spelke, E. S. (2000). Large number discrimination in 6-month-old infants. Cognition, 74(1), B1-B11.

Xu, F., Spelke, E. S., \& Goddard, S. (2005). Number sense in human infants. Developmental Science, 8(1), 88-101.

Xu, Y., Regier, T., \& Newcombe, N. S. (2017). An adaptive cue combination model of human spatial reorientation. Cognition, 163, 56-66. 